\title{
Hedgehog signaling in animal development: paradigms and principles
}

\author{
Philip W. Ingham ${ }^{1,3}$ and Andrew P. McMahon ${ }^{2,3}$ \\ ${ }^{1}$ Centre for Developmental Genetics, University of Sheffield, Sheffield S10 2TN, UK; ${ }^{2}$ Department of Cellular \\ and Developmental Biology, Harvard University, Cambridge, Massachusetts 02138, USA
}

Since their isolation in the early 1990s, members of the Hedgehog family of intercellular signaling proteins have come to be recognized as key mediators of many fundamental processes in embryonic development. Their activities are central to the growth, patterning, and morphogenesis of many different regions within the body plans of vertebrates and insects, and most likely other invertebrates. In some contexts, Hedgehog signals act as morphogens in the dose-dependent induction of distinct cell fates within a target field, in others as mitogens regulating cell proliferation or as inducing factors controlling the form of a developing organ. These diverse functions of Hedgehog proteins raise many intriguing questions about their mode of operation. How do these proteins move between or across fields of cells? How are their activities modulated and transduced? What are their intracellular targets? In this article we review some well-established paradigms of Hedgehog function in Drosophila and vertebrate development and survey the current understanding of the synthesis, modification, and transduction of Hedgehog proteins.

Embryological studies over much of the last century that relied primarily on the physical manipulation of cells within the developing embryo or fragments of the embryo in culture, provided many compelling examples for the primacy of cell-cell interactions in regulating invertebrate and vertebrate development. The subsequent identification of many of the signaling factors that mediate cellular communication has led to two general conclusions. First, although there are many important signals, most of these fall into a few large families of secreted peptide factors: the Wnt (Wodarz and Nusse 1998), fibroblast growth factor (Szebenyi and Fallon 1999), TGF- $\beta$ superfamily (Massague and Chen 2000), plateletderived growth factor (Betsholtz et al. 2001), ephrin (Bruckner and Klein 1998), and Hedgehog families. Second, parallel studies in invertebrate and vertebrate systems have shown that although the final outcome might

We dedicate this review to the memory of our dear friend and colleague Rosa Beddington, whose encouragement led to our initial collaboration. ${ }^{3}$ Corresponding authors.

E-MAIL p.w.ingham@sheffield.ac.uk; FAX 0114-222-288.

E-MAIL amcmahon@biosun.harvard.edu; FAX (617) 496-3763.

Article and publication are at http://www.genesdev.org/cgi/doi/10.1101/ gad. 938601 . look quite different (e.g., a fly vs. a mouse), there is a striking conservation in the deployment of members of the same signaling families to regulate development of these seemingly quite different organisms. This review focuses on one of the most intriguing examples of this phenomenon, that of the Hedgehog family.

As with many of the advances in our understanding of the genetic regulation of animal development, hedgehog (hh) genes owe their discovery to the pioneering work of Nüsslein-Volhard and Wieschaus (1980). In their screen for mutations that disrupt the Drosophila larval body plan, these authors identified several that cause the duplication of denticles (spiky cuticular processes that decorate the anterior half of each body segment) and an accompanying loss of naked cuticle, characteristic of the posterior half of each segment (see Fig. 1). The ensuing appearance of a continuous lawn of denticles projecting from the larval cuticle evidently suggested the spines of a hedgehog to the discoverers, hence the origin of the name of one of these genes. Other loci identified by mutants with this phenotype included armadillo, gooseberry, and wingless (wg). In contrast, animals mutant for the aptly named naked gene showed the converse phenotype, with denticle belts replaced by naked cuticle in every segment. On the basis of these mutant phenotypes, Nüsslein-Volhard and Wieschaus (1980) proposed that these so-called segment-polarity genes regulate pattern within each of the segments of the larval body, individual genes acting within distinct subregions of the emerging segmental pattern.

The first important breakthrough in unraveling how segment-polarity genes act came in the mid-1980s with the cloning of two members of the class, wingless and engrailed (en). Wg was shown to be the ortholog of the vertebrate proto-oncogene int1 (subsequently renamed Wnt 1 and the founder member of the Wnt family of secreted peptide factors; Rijsewijk et al. 1987), whereas the sequence of en revealed that it encodes a homeodomaincontaining transcription factor (Fjose et al. 1985; Poole et al. 1985). Intriguingly, the two genes were found to be expressed in adjacent narrow stripes of cells in each segment (Martinez Arias et al. 1988). A close spatial relationship between Wnt1 and En expression domains was also reported in the primordial midbrain and hindbrain of the vertebrate embryo (McMahon et al. 1992). Analy- 
A
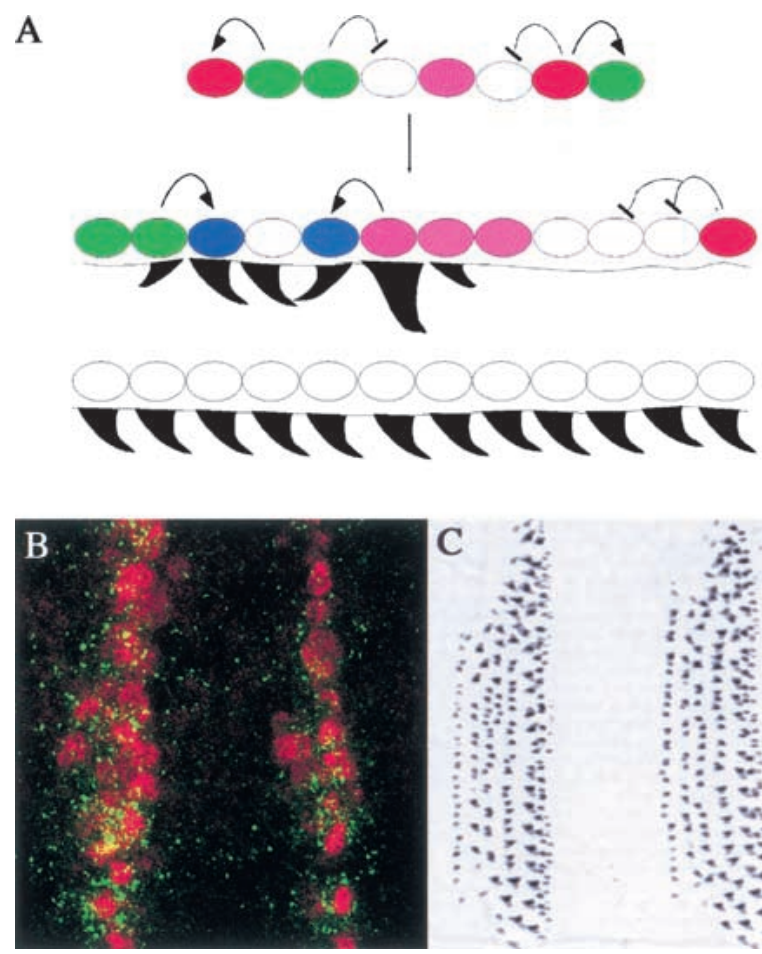

Figure 1. Short-range signaling by Hedgehog in the embryonic ectoderm of Drosophila. (A) Schematic representation of the gene expression domains and cellular interactions that generate the larval cuticle pattern shown in $C$. Hh (green) is secreted by a narrow stripe of cells that marks the boundary of each segment in the developing embryo. Cells anterior to each Hh domain respond to the signal by maintaining $w g$ transcription (red). Cells that are posterior to each Hh domain respond initially by repressing Ser expression (pink). Following cell division (middle array), wg expression is maintained anterior to the $\mathrm{Hh}$ domain, and secreted Wg acts on neighboring cells to suppress denticle formation. Expression of rho (blue) is induced in two distinct domains by $\mathrm{Hh}$ and by Ser, respectively. This generates a series of unique cellular interfaces that act to specify the size and shape of the denticles that decorate the cuticle. In the absence of Hh activity (lower array), none of these unique gene expression domains is established, leading to the generation of a uniform field of denticles. $(B)$ Confocal image of two adjacent segments in a developing Drosophila embryo showing the distribution of Hh protein (green) around the cells from which it is secreted, marked by the expression of $\mathrm{EN}$ homeodomain protein (red). (C) phase contrast image of the ventral denticle belts of two abdominal segments in a newly hatched Drosophila larva.

sis of the changes in $w g$ and en expression in segmentpolarity mutant embryos led to the formulation of a model according to which mutual interactions between wg- and en-expressing cells play a crucial role in maintaining the integrity of individual segmental units (or parasegments; DiNardo et al. 1988; Martinez Arias et al. 1988). Several lines of evidence pointed to the product of the $h h$ gene as the best candidate for the signal mediating the postulated inductive effects of the En-expressing cells (Ingham 1991). The cloning of $h h$ was thus eagerly awaited, not only by those in the Drosophila community anxious to piece together the puzzle of segmental pat- tern, but also by vertebrate developmental biologists who were keen to see whether Hedgehog, Wnt1, and Engrailed proteins might be involved in similar interactions in the developing brain.

In 1992 three groups showed that Drosophila hh encodes a putative secreted peptide whose expression is confined to engrailed-expressing cells in the posterior compartment of each segment primordium (Lee et al. 1992; Mohler and Vani 1992; Tabata et al. 1992). An additional report confirming these findings appeared the following year (Tashiro et al. 1993). These studies showed that $h$ h expression is wingless-dependent, consistent with the reciprocal signaling model alluded to above (see Fig. 1). Significantly, hh expression was also observed in the posterior compartment of the wing and leg imaginal discs (Lee et al. 1992), suggesting a broader role for $\mathrm{Hh}$ signaling in the development of these appendages. Indeed, it is now clear that $\mathrm{Hh}$ is a central patterning signal in the wing (Mohler 1988; Basler and Struhl 1994; Tabata and Kornberg 1994), leg (Diaz-Benjumea et al. 1994), and eye discs (Heberlein et al. 1995; Dominguez 1999), as well as regulating several other processes, including germ-cell migration (Deshpande et al. 2001), and development of the optic lamina (Huang and Kunes 1996, 1998) gonad (Forbes et al. 1996; Zhang and Kalderon 2000), abdomen (Struhl et al. 1997), gut (Pankratz and Hoch 1995), and tracheal system (Glazer and Shilo 2001).

hh genes have been identified in several other invertebrate species including the leech and sea urchin /Chang et al. 1994) as well as in the cephalochordate amphioxus (Fig. 2; Shimeld 1999). One notable exception is the nematode worm Caenorhabditis elegans, which has no hh ortholog (Aspock et al. 1999) but does possess several genes encoding proteins homologous to the $\mathrm{Hh}$ receptor Patched (Kuwabara et al. 2000).

Vertebrate hedgehog genes were first reported in 1993, following a cross-species (fish, chick, and mouse) collaborative effort involving three groups (Echelard et al. 1993; Krauss et al. 1993; Riddle et al. 1993); additional reports of $h \mathrm{~h}$ homologs appeared the following year (Chang et al. 1994; Roelink et al. 1994). There were several surprises in these initial findings. First, unlike the fly, which has a single $h h$ gene, there are several related genes in vertebrate species (Fig. 2). Three hh genes were identified in the mouse: Desert hedgehog (Dhh), Indian hedgehog (Ihh), and Sonic hedgehog (Shh) (Echelard et al. 1993). Dhh is most closely related to Drosophila hedgehog; Ihh and Shh are more related to one another, representing a more recent gene duplication event (Fig. 2). Further duplication events appear to have occurred in teleosts within the Shh and Ihh classes (Fig. 2; Krauss et al. 1993; Ekker et al. 1995b; Currie and Ingham 1996). Second was the evocative expression of Shh in three key signaling centers in the vertebrate embryo: the notochord, the floor plate, and the zone of polarizing activity (ZPA), a population of apical, posterior mesenchyme cells in the limb bud, but not within the mid/hindbrain region where Wnt1/Engrailed interactions had been observed.

Earlier studies of neural plate patterning had shown 


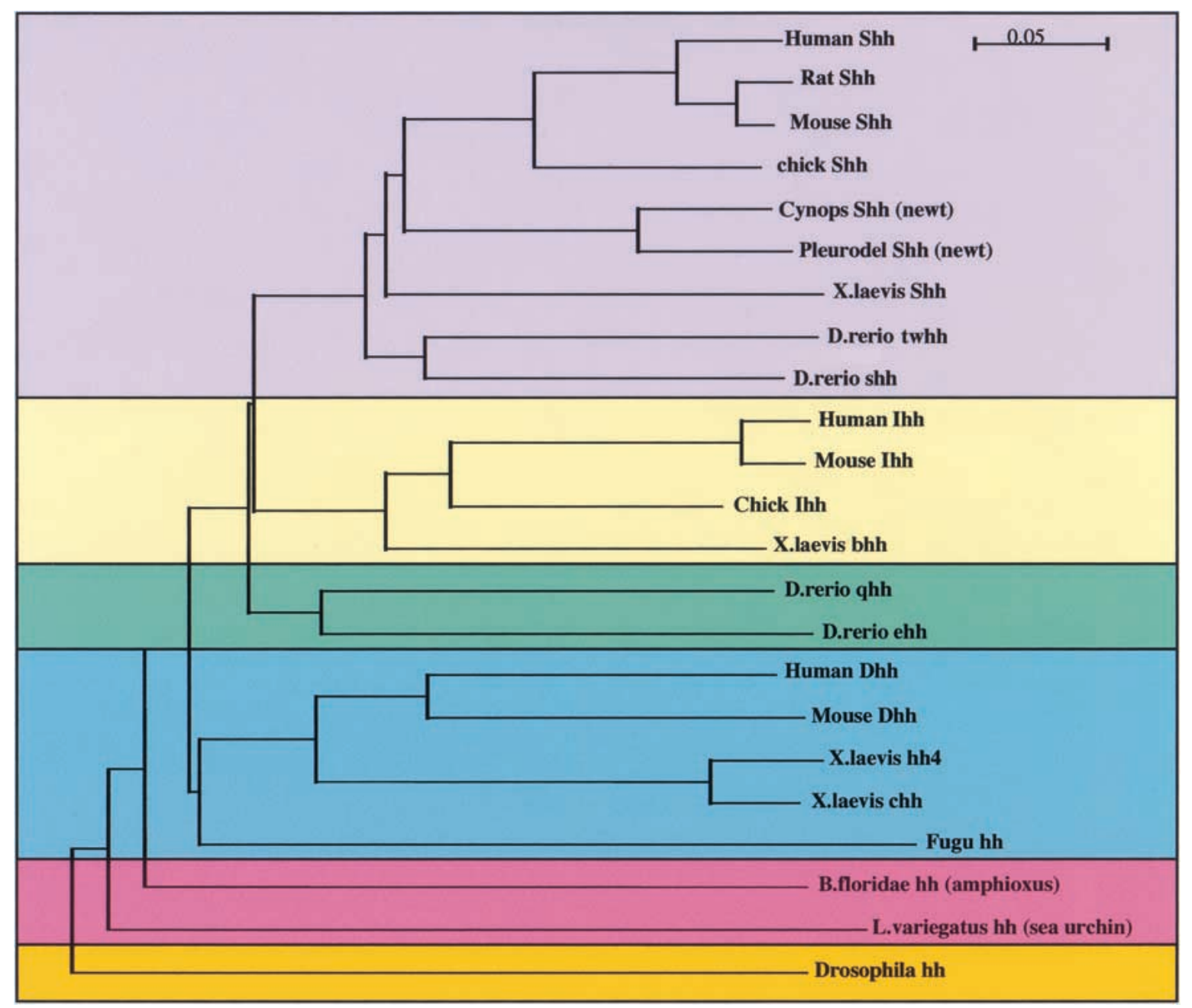

Figure 2. Phylogenetic relationship of members of the Hh protein family from different vertebrate species, cephalochordates and Drosophila (adapted from Borycki 2001). Amniote Hhs fall into three distinct subgroups: Sonic (lilac), Indian (yellow), and Desert (blue). The zebrafish Ehh (Currie and Ingham 1996) and Qhh (T. Qiao and P.W. Ingham, unpubl.) are divergent members of the Indian subgroup (green).

the importance of notochord and floor plate signals in ventralizing the developing neural tube (for review, see Placzek 1995), whereas in the limb, many lines of evidence pointed to the role of the ZPA in the regulation of anterior polarity (for review, see Tabin 1991). The discovery of Shh therefore not only provided a candidate for the active principle that patterns the neural tube and limb, but in addition suggested a molecular link in the development of these distinct parts of the vertebrate body plan. Ectopic expression studies in the frog, fish, mouse, and chick furnished the initial evidence that Shh regulates ventral polarity in the neural tube and anterior-posterior polarity in the limb. Dorsal expression of Shh in the neural tube resulted in the induction of ventral marker gene expression (Echelard et al. 1993; Krauss et al. 1993; Roelink et al. 1994), whereas anterior expression of Shh in the limb mesenchyme produced a mirror image duplication of limb pattern resembling those produced by anterior grafts of ZPA cells (Riddle et al. 1993;
Chang et al. 1994). These key preliminary observations have subsequently been explored in considerable depth to reveal many of the mechanistic principles underlying the development of both structures. Furthermore, the intervening years have seen $\mathrm{Hh}$ proteins implicated in a plethora of processes in the developing embryo (see Table 1). Indeed, there are few parts of the vertebrate body plan that are not influenced in some way by a $\mathrm{Hh}$ signal.

Although the precise cellular roles of $\mathrm{Hh}$ signals are still under scrutiny, it is clear that they can elicit different responses depending on the context in which the signals operate. Thus, Hh signals have been shown to regulate cell fate specification, cell proliferation, and cell survival in different target cells (see Table 1). Signaling can be short- and long-range, direct and indirect /through the activation of a signaling relay), and importantly, concentration-dependent, evoking distinct molecular responses at discrete concentration thresholds (a classic 
Table 1. Vertebrate Hedgehog functions

\begin{tabular}{|c|c|c|c|}
\hline $\begin{array}{l}\text { Tissue/cell } \\
\text { type/organ }\end{array}$ & Ligand & Nature of role & Reference $^{a}$ \\
\hline \multirow[t]{2}{*}{$\begin{array}{l}\text { Angiogenesis/ } \\
\text { vasculogenesis }\end{array}$} & Ihh & $\begin{array}{l}\text { Stimulates endothelial cell production in } \\
\text { yolk sac }\end{array}$ & Dyer et al. 2001 \\
\hline & Shh & Induces angiogenesis & Pola et al. 2001 \\
\hline \multirow[t]{2}{*}{ Blood cells } & Shh & $\begin{array}{l}\text { Proliferation stem cells, modulation } \\
\text { hematopoietic and thymocyte } \\
\text { differentiation }\end{array}$ & $\begin{array}{l}\text { Detmer et al. 2000; Outram et al. 2000; } \\
\text { Bhardwaj et al. } 2001\end{array}$ \\
\hline & Ihh & Activation of hematopoiesis & Dyer et al. 2001 \\
\hline \multirow[t]{2}{*}{ Bone and cartilage } & Shh & $\begin{array}{l}\text { Induction early chondrogenic factors in } \\
\text { somite proliferation/survival axial } \\
\text { chondrogenic precursors }\end{array}$ & $\begin{array}{l}\text { Fan and Tessier-Lavigne 1994; Johnson et } \\
\text { al. 1994; Chiang et al. 1996; Teillet et al. } \\
\text { 1998; Murtaugh et al. 1999; Zhang et al. } \\
2001\end{array}$ \\
\hline & Ihh & $\begin{array}{l}\text { Coordination of proliferation/ } \\
\text { differentiation in endochondral skeleton }\end{array}$ & $\begin{array}{l}\text { Lankse et al. 1996; Vortkamp et al. 1996; } \\
\text { St-Jacques et al. 1999; Enomoto-Iwato et } \\
\text { al. 2000; Karp et al. 2000; Chung et al. } \\
\text { 2001; Long et al. 2001; Yoshida et al. } \\
2001\end{array}$ \\
\hline $\begin{array}{l}\text { Cement gland } \\
\text { induction }\end{array}$ & $\mathrm{X}-\mathrm{bhh}^{\mathrm{b}}, \mathrm{X}-\mathrm{chh}^{\mathrm{c}}$ & $\begin{array}{l}\text { Anteriorizes Xenopus neural and } \\
\text { non-neural ectoderm }\end{array}$ & Ekker et al. 1995a; Lai et al. 1995 \\
\hline Cerebellum & Shh & $\begin{array}{l}\text { Proliferation of granule cell precursors, } \\
\text { differentiation of Bergmann glia }\end{array}$ & $\begin{array}{l}\text { Dahmane and Ruiz-i-Altaba 1999; Wallace } \\
\text { 1999; Wechsler-Teya and Scott 1999; } \\
\text { Kenney and Rowitch 2000; Pons et al. } \\
2001\end{array}$ \\
\hline \multirow[t]{2}{*}{ Eye } & $\begin{array}{l}\text { Shh }(\text { Ihh, Dhh, } \\
\text { twhh }^{\mathrm{d}}\end{array}$ & $\begin{array}{l}\text { Stimulates and inhibits retinal } \\
\text { neurogenesis astrocyte proliferation in } \\
\text { optical nerve, retinal precursor } \\
\text { proliferation }\end{array}$ & $\begin{array}{l}\text { Jensen and Wallace 1997; Levine et al. } \\
\text { 1997; Wallace and Raff 1999; Neumann } \\
\text { and Nüsslein-Volhard 2000; Stenkamp et } \\
\text { al. 2000; Zhang and Yang 2001a,b }\end{array}$ \\
\hline & Shh and/or twhh & Induction proximal fates in the eye fields & Ekker et al. 1995; Macdonald et al. 1995 \\
\hline \multirow[t]{2}{*}{ Gut } & Shh & $\begin{array}{l}\text { Separation of trachea and esophagus, A-P } \\
\text { patterning gut tube }\end{array}$ & $\begin{array}{l}\text { Roberts et al. 1995; Litingtung et al. 1998; } \\
\text { Pepicelli et al. 1998 }\end{array}$ \\
\hline & $\begin{array}{l}\text { Ihh and/or Shh } \\
\text { (unique and } \\
\text { redundant } \\
\text { activities) }\end{array}$ & $\begin{array}{l}\text { Proliferation mesenchyme, inhibition of } \\
\text { mesenchyme differentiation, radial } \\
\text { patterning of gut tube }\end{array}$ & $\begin{array}{l}\text { Apelqvist et al. 1997; Ramalho-Santos et } \\
\text { al. 2000; Sukegawa et al. } 2000\end{array}$ \\
\hline $\begin{array}{l}\text { Gonads/external } \\
\text { genitalia }\end{array}$ & Dhh & $\begin{array}{l}\text { Peritubular cell development, maturation } \\
\text { of testes, Sertoli-Leydig cell interactions, } \\
\text { male germ line development, } \\
\text { masculinization }\end{array}$ & $\begin{array}{l}\text { Bitgood et al. 1996; Clark et al. 2000; } \\
\text { Umehara et al. } 2000\end{array}$ \\
\hline Hair/feather & Shh & $\begin{array}{l}\text { Follice/feather morphogenesis, polarity of } \\
\text { feather, Telogen to anogen switch in } \\
\text { hair follicle }\end{array}$ & $\begin{array}{l}\text { Ting-Berreth and Chuong 1996; Morgan et } \\
\text { al. 1998; St-Jacques et al. 1998; Chiang } \\
\text { et al. 1999; Karlsson et al. 1999; Sato et } \\
\text { al. } 1999\end{array}$ \\
\hline Heart & $\begin{array}{l}\text { Shh or Ihh } \\
\text { (redundant } \\
\text { activities) }\end{array}$ & Cardiac morphogenesis & Zhang et al. 2001 \\
\hline $\begin{array}{l}\text { Lateral } \\
\text { Asymmetry }\end{array}$ & $\begin{array}{l}\text { Shh }^{\mathrm{e}} \\
\text { Shh or Ihh } \\
\text { (redundant } \\
\text { activities) }\end{array}$ & $\begin{array}{l}\text { Regulation of L/R asymmetry (left } \\
\text { pathway) }\end{array}$ & $\begin{array}{l}\text { Levin et al. 1995; Meyers and Martin 1999; } \\
\text { Schilling et al. 1999; Tsukui et al. 1999; } \\
\text { Monsoro-Burq and Le Douarin 2001; } \\
\text { Zhang et al. } 2001\end{array}$ \\
\hline Limbs & Shh & $\begin{array}{l}\text { A-P patterning of skeleton, outgrowth of } \\
\text { limb-bud }\end{array}$ & $\begin{array}{l}\text { Riddle et al. 1993; Laufer et al. 1994; } \\
\text { Niswander et al. 1994; Yang et al. 1997; } \\
\text { Neumann et al. 1999; Drossopoulou et } \\
\text { al. 2000; Fernandez-Teran et al. 2000; } \\
\text { Sanz-Ezquerro and Tickle 2000; Wang et } \\
\text { al. 2000; Chiang et al. 2001; Kraus et al. } \\
\text { 2001; Lee et al. 2001; Lewis et al. 2000; } \\
\text { Zeng et al. } 2001\end{array}$ \\
\hline
\end{tabular}


Table 1. Continued

\begin{tabular}{|c|c|c|c|}
\hline $\begin{array}{l}\text { Tissue/cell } \\
\text { type/organ }\end{array}$ & Ligand & Nature of role & Reference $^{a}$ \\
\hline Lung & Shh & $\begin{array}{l}\text { Branching epithelium, proliferation/ } \\
\text { survival mesenchyme }\end{array}$ & $\begin{array}{l}\text { Bellusci et al. 1997; Littingtung et al. } \\
\text { 1998; Pepicelli et al. } 1998\end{array}$ \\
\hline \multirow[t]{2}{*}{ Muscle } & Shh & $\begin{array}{l}\text { Induction/proliferation/survival epaxial } \\
\text { muscle precursors, fiber-type identity, } \\
\text { regulation smooth muscle differentiation }\end{array}$ & $\begin{array}{l}\text { Johnhson et al. 1994; Munsterberg et al. } \\
\text { 1995; Blagden et al. 1997; Duprez et al. } \\
\text { 1998; Pepicelli et al. 1998; Borycki et al. } \\
\text { 1999; Duprez et al. 1999; Lewis et al. } \\
\text { 1999; Norris et al. 2000; Sukegawa et al. } \\
\text { 2000; Coutelle et al. 2001; Kruger et al. } \\
\text { 2001 }\end{array}$ \\
\hline & Echidna, twhh & Muscle/fiber-type identity & Currie and Ingham 1996; Du et al. 1996 \\
\hline Neural Crest & Shh & $\begin{array}{l}\text { Survival cranial neural crest, cranial facial } \\
\text { morphogenesis, proliferation/ } \\
\text { differentiation sympathetic cells }\end{array}$ & $\begin{array}{l}\text { Helms et al. 1997; Ahlgren and } \\
\text { Bronner-Fraser 1999; and Williams et al. } \\
\text { 2000; Garg et al. } 2001\end{array}$ \\
\hline \multirow[t]{2}{*}{ Neurons } & Shh & $\begin{array}{l}\text { Induction of specific ventral neural cell } \\
\text { types, proliferation/survival/death neural } \\
\text { precursors }\end{array}$ & $\begin{array}{l}\text { Echelard et al. 1993; Kraus et al. 1993; } \\
\text { Roelink et al. 1994; Ericson et al. 1995; } \\
\text { Hynes et al. 1995; Marti et al. 1995; } \\
\text { Roelink et al. 1995; Wang et al. 1995; } \\
\text { Belloni et al. 1996; Chiang et al. 1996; } \\
\text { Ericson et al. 1997; Dale et al. 1997; } \\
\text { Kohtz et al. 1998; Ye et al. 1998; Briscoe } \\
\text { et al. 1999; Odent et al. 1999; } \\
\text { Oppenheim et al. 1999; Rowitch et al. } \\
\text { 1999; Briscoe et al. 2000; Gunhaga et al. } \\
\text { 2000; Hynes et al. 2000; Litingtung et al. } \\
\text { 2000; Watanabe et al. 2000; Agarwala et } \\
\text { al. 2001 }\end{array}$ \\
\hline & twhh & Induction motor neuron & Bingham et al. 2001 \\
\hline Olfactory & Shh & Olfactory pathway formation & LaMantia et al. 2000 \\
\hline Oligodendrocytes & Shh & $\begin{array}{l}\text { Proliferation/differentiation/survival of } \\
\text { precursors }\end{array}$ & $\begin{array}{l}\text { Poncet et al. 1996; Pringle et al. 1996; } \\
\text { Orentas et al. 1999; Lu et al. 2000; } \\
\text { Davies and Miller 2001; Soula et al. } \\
\text { 2001; Nery et al. } 2001\end{array}$ \\
\hline Pancreas & Shh & $\begin{array}{l}\text { Inhibition of pancreatic anlagen formation, } \\
\text { insulin production } \\
\text { Specification of pancreas anlagen (in fish) }\end{array}$ & $\begin{array}{l}\text { Apelqvist et al. 1997; Kim and Melton } \\
\text { 1997; Hebrok et al. 2000; Deutsch } \\
\text { et al. 2001; Thomas et al. 2001; } \\
\text { Roy et al. } 2001\end{array}$ \\
\hline Peripheral nerves & Dhh & Formation peripheral nerve sheath & $\begin{array}{l}\text { Parmantier et al. 1999; Umehara et al. } \\
2000\end{array}$ \\
\hline Pituitary & Shh & $\begin{array}{l}\text { Inhibits transdifferentiation to lens, } \\
\text { proliferation/cell type determination }\end{array}$ & Kondoh et al. 2000; Treier et al. 2001 \\
\hline Prostate & Shh & Growth and ductal morphogenesis & Podlasek et al. 1999 \\
\hline Tooth & Shh & Growth, polarity and morphogenesis & $\begin{array}{l}\text { Mo et al. 1997; Dassule and McMahon } \\
\text { 1998; Hardcastle et al. 1999; Dassule et } \\
\text { al. 2000; Zhang et al. } 2000\end{array}$ \\
\hline Tongue & Shh & Maintenance/renewal taste buds & Miura et al. 2001 \\
\hline
\end{tabular}

${ }^{a}$ Due to space limitations only a subset of the literature can be cited.

${ }^{\mathrm{b}}$ Xenopus - banded hedgehog (X-bhh).

${ }^{\mathrm{c} X e n o p u s-c e p h a l i c ~ h e d g e h o g}$ (X-chh).

${ }^{\mathrm{d} S h h}$, Ihh, Dhh and tiggywinkle hedgehog (twhh) have all been shown to be expressed in the eye. Most experimental manipulations have used Shh. Whether action of Shh in these assays reflects Shh activity in vivo or activity of other Hedgehogs is not absolutely clear. ${ }^{e}$ Genetic studies in mice indicate that Shh and Ihh have overlapping roles. Studies in other species (chiefly chick) suggest Shh is key factor.

morphogen activity). Perhaps not surprisingly given their key regulatory actions, misregulation of Hh signal- ing has been shown to contribute to various pathologies, most notably various cancers including basal cell carci- 
noma (for reviews, see Ingham 1998; Taipale and Beachy 2001), the most prevalent cancer in the Caucasian population. Clearly it is beyond the scope of this review to provide a comprehensive account of all recorded instances of Hh signaling. Rather, we focus on a few wellestablished paradigms of $\mathrm{Hh}$ function in flies and vertebrates and then consider some of the mechanistic principles that have emerged from their study.

\section{Long- or short-range signaling?}

Local interactions in the embryonic ectoderm of Drosophila mediated by Hedgehog

The continuous lawn of denticles that characterizes $h h$ mutant embryos is indicative of a loss of antero-posterior positional information within each segment. Each denticle belt is normally composed of a series of rows of denticles having unique size, shape, and polarity, which thus provide precise markers of position along the antero-posterior axis of the segment (see Fig. 1). In hh mutants, this diversity of denticle type is lost, suggesting that all the epidermal cells have adopted the same positional identity. Such an effect would be consistent with Hh acting as a classical morphogen, specifying positional information across the segmental field in a dose-dependent manner. Although the restricted expression of $\mathrm{Hh}$ at the posterior boundary of the segments fitted with this view, analysis of the regulation of the first two Hh target genes to be identified-wg and patched (ptc) — did not. The spatial regulation of both of these genes in response to $\mathrm{Hh}$ activity instead strongly suggested that the effects of $\mathrm{Hh}$ are restricted to the nearest neighbors of expressing cells (Fig. 1). Moreover, the fact that ptc is activated on either side of each $\mathrm{Hh}$ domain indicated that the signal emanates from its source symmetrically, a characteristic difficult to reconcile with the notion of a monotonic gradient of activity across each segment (Hidalgo and Ingham 1990; Ingham et al. 1991; Ingham and Hidalgo 1993; Fietz et al. 1995).

Because $w g$ also encodes a secreted protein that, in other contexts, has morphogen-like properties, these findings could in principle be accommodated by postulating a role for $\mathrm{Hh}$ in inducing the source of a long-range signaling activity encoded by wg (Sampedro et al. 1993). An alternative view, however, envisaged positional identity being specified in a different manner, emerging via a sequence of short-range inductive interactions that would be mediated by signals such as $\mathrm{Hh}$ and $\mathrm{Wg}$ (Martinez Arias et al. 1988). Support for this latter type of model has come from the detailed analysis of other recently identified targets of $\mathrm{Hh}$ and $\mathrm{Wg}$ activity in the embryonic ectoderm. Of particular significance are the Ser and rho genes, which encode a Notch ligand and an activator of EGFR ligands, respectively, and are required for the differentiation of specific denticle rows in each segment (Wiellette and McGinnis 1999). Elegant studies have revealed an exquisitely fine-grained pattern of expression of these genes that arises in a defined temporal sequence in response to the short-range activity of $\mathrm{Hh}$ and $\mathrm{Wg}$, as well as of Ser itself (Alexandre et al. 1999). Thus, following the mutual stabilization of $\mathrm{Wg}$ and $\mathrm{Hh}$ expression, both signals act locally to repress Ser in cells adjacent to their expression domains. This pattern is maintained during the subsequent round of cell division to yield a localized source of Ser activity within a domain of uncommitted cells; narrow stripes of rho expression are then established within this domain by the local inductive interactions mediated both by $\mathrm{Hh}$ and Ser. In this way, a series of unique interfaces between gene expression domains are established that can account for all of the different denticle types within each segment (see Fig. 1).

\section{Long-range signaling in Drosophila imaginal discs: direct and indirect effects}

In contrast to the larval segments, there is compelling evidence that in the primordium of the wing, Hh exerts a long-range effect on positional specification by regulating the expression of a morphogen, Decepantaplegic (Dpp), a member of the TGF- $\beta$ superfamily. Moreover, it is clear that in this context, Hh itself can act over several cell diameters to activate different target genes in a dosedependent manner, providing a paradigm for its own morphogen-like properties in the vertebrate neural tube and limb bud (as discussed below).

Like all adult appendages in the fly, the wing derives from a monolayer epithelium known as an imaginal disc that grows inside the larva and everts during metamorphosis. Each imaginal disc is subdivided by a lineage restriction into an anterior $(\mathrm{A})$ and posterior $(\mathrm{P})$ compartment, the expression of $\mathrm{Hh}$ being restricted exclusively to cells of the posterior compartment (see Fig. 3). Expression of the $d p p$ gene is confined to a narrow strip of cells just anterior to the $\mathrm{A} / \mathrm{P}$ compartment boundary in the presumptive wing pouch region of the disc (Fig. 3). From this localized source, the protein spreads in both directions (Teleman and Cohen 2000), generating a gradient of activity across each compartment that directs the spatially restricted expression of target genes such as omb and spalt (Nellen et al. 1996). The restricted expression of $d p p$ close to the boundary depends critically on the activity of Hh protein secreted by nearby posterior compartment cells, as evidenced both by the loss of $d p p$ expression when Hh activity is eliminated and by the ectopic expression of $d p p$ when $\mathrm{Hh}$ is inappropriately expressed in the anterior compartment (Basler and Struhl 1994; Capdevila and Guerrero 1994; Tabata and Kornberg 1994; Ingham and Fietz 1995; Zecca et al. 1995). In addition, Hh attenuates the response of the Dpp-expressing cells to their own signal by down-regulating expression of the Dpp receptor (Tanimoto et al. 2000). Detailed phenotypic analysis revealed that Dpp activity alone cannot account for all of the pattern elements induced by Hh activity, pointing to a requirement for additional targets of Hh signaling in patterning the wing (Mullor et al. 1997). Three such targets are vein, which encodes an EGFR ligand (Schnepp et al. 1996), and en and collier (col), both of which encode transcription factors (Poole et 

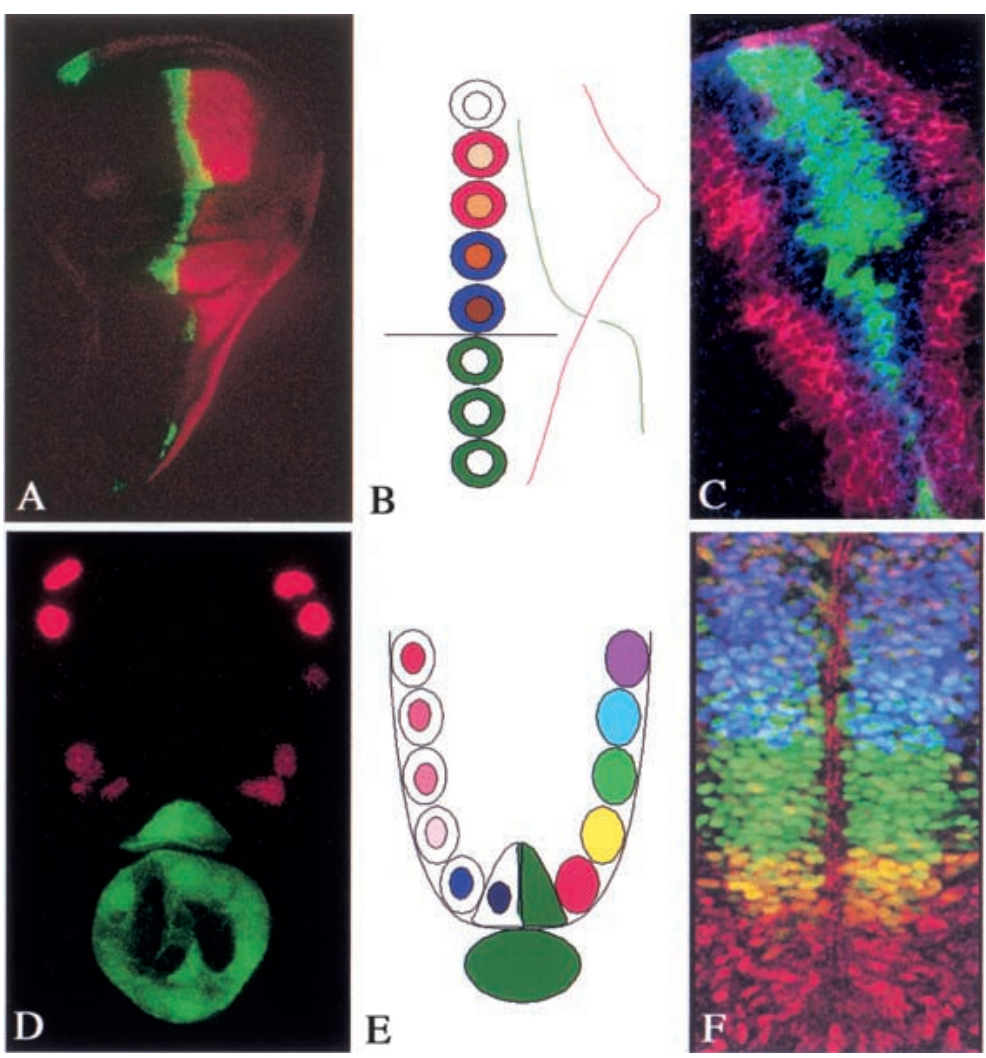

Figure 3. Morphogen-like properties of $\mathrm{Hh}$ in the Drosophila imaginal disc and vertebrate neural tube. (A) The wing imaginal disc is subdivided into an anterior and a posterior compartment, the latter being characterized by the expression of EN protein (red). Cells along the boundary between the two compartments express the $d p p$ gene (green) in response to $\mathrm{Hh}$ secreted by posterior compartment cells. $(B)$ Schematic representation of a cross section through the wing disc in the vicinity of the compartment boundary showing the expression domain of Hh (green) and its targets in the anterior compartment. Cells immediately adjacent to the compartment boundary (horizontal line) receive the highest levels of Hh activity (represented by the green curve). This promotes nuclear import of the activated form of the $\mathrm{Ci}$ transcription factor (represented by dark brown shading), which, in turn, activates transcription of target genes such as ptc and collier (represented by the blue cytoplasmic shading). Cells more distal to the boundary receive lower levels of $\mathrm{Hh}$ and accordingly import lower levels of active $\mathrm{Ci}$ into their nuclei (represented by light brown). These lower levels of activated $\mathrm{Ci}$ together with the absence of the repressor form of $\mathrm{Ci}$ result in activation of the $d p p$ gene (red cytoplasmic shading). Dpp protein secreted by these cells establishes a bell-shaped distribution (red curve) that specifies cell identity in both compartments of the wing. Expression of $d p p$ is repressed in more anteriorly located cells by the nuclear accumulation of the repressor form of Ci. It should be noted that owing to the lability of the fully activated form of $\mathrm{Ci}$, the distribution of full-length Ci protein observable in situ appears inverse to that represented here (see Wang and Holmgren 1999). (C) Differential response of anterior compartment cells in the wing disc to a source of Hh protein (green). Cells immediately adjacent to the source of Hh activate ptc expression (blue), whereas $d p p$ expression is activated only some 2-3 cell diameters away from the source. These cells also express Ptc but at lower levels, obscured by the $d p p$ reporter gene signal. (D) Shh is expressed in the notochord and floor plate of vertebrate embryos, as revealed here by the expression of a Shh::GFP reporter gene in the zebrafish embryo, and specifies the identity of motoneurons (faint red) and other cells in the overlying neural tube by establishing domains of different homeodomain protein expression $(F)$. This is shown schematically in panel $E$ : on the right, the different colored cells represent the distinct cell identities established by the different combinations of homeodomain proteins. These patterns of expression are established in response to different levels of Shh protein, which, in turn, leads to different levels of Gli1 and/or Gli2 transcriptional activators (blue nuclei) or Gli3 transcriptional repressor (red nuclei) within the nuclei of responding cells.

al. 1985; Crozatier et al. 1996). Each of these genes is essential for the specification of pattern elements close to the $\mathrm{A} / \mathrm{P}$ compartment border that therefore might be expected to require the highest levels of Hh activity for their differentiation. The Vein protein is specifically required for the induction of two wing veins (L3 and L4) that flank the central region of the wing (Mohler et al. 2000), whereas Col activity is essential for the specification of this region itself (Vervoort et al. 1999; Mohler et al. 2000). Although the activity of $e n$ had long been considered to be restricted to the posterior compartment of the wing, an elegant study by Hidalgo (1994) revealed an additional function in the anterior compartment, where it suppresses the differentiation of marginal bristles between L3 and L4. Like $d p p$, all three of these genes are expressed at the $\mathrm{A} / \mathrm{P}$ border, but significantly, their expression domains are offset from that of $d p p$, directly abutting the Hh-secreting cells in the $\mathrm{P}$ compartment (see Fig. 3). These distinct domains of expression imply a differential response of target genes to Hh levels, as originally noted by Ingham and Fietz (1995); subsequent stud- ies have established that $d p p, c o l$, and $e n$ are induced by different levels of Hh activity (see Fig. 3; Mullor et al. 1997; Strigini and Cohen 1997; Vervoort et al. 1999). This dosage-dependent effect of $\mathrm{Hh}$ is also reflected in the graded expression of $p t c$ at the compartment boundary and appears to extend over at least 10 cell diameters.

\section{Long-range patterning of the vertebrate neural tube}

In vertebrate embryos, cells within the neural tube adopt distinct identities by reference to signaling centers located at either end of its dorso-ventral axis. Various members of the TGF- $\beta$ superfamily produced by the dorsal ectoderm and roof plate of the dorsal neural tube appear to be the dominant influence in the specification of dorsal cell identities (for review, see Lee and Jessell 1999). Ventrally, two sources of Shh, the notochord, a mesodermal rod that underlies the ventral neural tube, and the floor plate, a specialized population of support cells at the ventral midline of the developing central nervous system, play a major role in specifying cell identity 
(for review, see Placzek 1995). The disposition of different ventral cell types in the developing spinal cord in relation to these two sources of Shh is shown in Figure 3. Shh is produced by both the notochord and floor plate; several lines of evidence point to its role as a long-range morphogen in neural tube patterning. First, direct observation of the distribution of Shh (Gritli-Linde et al. 2001) and expression of its conserved target Ptc1 (Goodrich et al. 1996; Marigo and Tabin 1996) show that Shh forms an activity gradient over the ventral half of the neural tube coincident with the patterning process. Second, Shh is both necessary (Marti et al. 1995; Chiang et al. 1996) and sufficient (Marti et al. 1995; Roelink et al. 1995) for the induction of distinct ventral cell identities in the spinal cord: initial studies focused on the ventro-medial floor plate and ventro-lateral motor neurons, but the generation of novel cell-type specific markers has expanded the repertoire (Jessell 2000). Third, cell-autonomous activation (Hynes et al. 2000) or inhibition (Briscoe et al. 2001) of Shh signaling within the neural tube indicates that the protein acts directly and at long range to specify cell fate. Fourth, the concentration threshold for induction of distinct neural progenitors in neural plate explants correlates closely with their position in the spinal cord: as the threshold increases, progenitors are positioned progressively closer to the midline sources of Shh production. Analysis of this latter phenomenon has relied on the response of uncommitted intermediate neural plate explants (principally from chick embryos) to purified recombinant Shh and in ovo electroporation of the neural tube, approaches that have been particularly valuable in determining how Shh regulates distinct cell fates. Together these data have led Jessell and colleagues (Briscoe et al. 2000) to propose a model in which dose-dependent activation (class II genes; Nkx6.1 and Nkx2.2) or repression (class I genes; Pax6, Irx3, Dbx2) of a diverse group of homeodomain-containing transcriptional regulators provides the initial response to Shh signaling (Fig. 3). Subsequently, mutual repressive interactions among these factors ensure the inheritance of a stable "homeodomain code" that dictates which neuronal subtype is formed. The role of Shh in patterning the ventral neural tube extends into regions of the brain where several cell identities have been shown to depend on ventrally derived Shh for their induction (see Table 1). Indeed, mutations that result in the loss of Shh activity in humans can lead to the generation of holoprosencephaly, a developmental defect that reflects the loss of ventral cell types in the forebrain (Belloni et al. 1996; Roessler et al. 1996).

\section{Shh and long-range patterning in the vertebrate limb}

As in the Drosophila wing imaginal disc, gain- and lossof-function experiments have implicated Shh in the specification of positional identity along the antero-posterior axis of the developing limb bud. In contrast to the situation in the neural tube, however, there is no evidence for any signaling influence opposing that of Shh; rather, AP pattern appears to be generated exclusively by reference to the ZPA from which Shh emanates.
Ectopic presentation of Shh in the anterior limb bud induces additional digits in a dose-dependent manner, increasing levels of Shh activity inducing progressively more digits of more posterior character (Yang et al. 1997). One complication in investigating the role of Shh in the limb by loss-of-function analysis comes from the requirement for Shh to maintain Fgf expression in the apical ectoderm and, consequently, continued skeletogenesis (Laufer et al. 1994; Niswander et al. 1994). As proximo-distal development is compromised when Shh activity is removed, it is difficult to design experimental approaches that completely remove a potential Shh polarizing signal but leave limb outgrowth intact. Nevertheless, using a conditional knock-down strategy, it has been possible to show that reduction in the levels of Shh expression within the ZPA results in a loss of the most posterior digits, consistent with their being specified by the highest levels of Shh activity (Lewis et al. 2001).

Although it is clear that the concentration of Shh is the primary determinant of anterior-posterior polarity in the vertebrate limb, what is less certain is whether Shh is the direct patterning signal throughout the digit-forming target field. Consistent with this possibility, direct analysis of Shh distribution (Lewis et al. 2001; Zeng et al. 2001) as well as of the domains of expression of its target genes (Marigo et al. 1996c; Lewis et al. 2001) indicates that the protein can spread for many cell diameters away from its restricted source within the ZPA. But, as in the Drosophila wing, limb, and eye discs, there is some evidence for a signaling relay that uses Bmp2 (Duprez et al. 1996; Drossopoulou et al. 2000), a close relative of Dpp; this situation contrasts with the neural tube, where Bmp signaling plays an opposite role to Shh in the patterning of dorsal cell types (Lee and Jessell 1999). Despite possible differences in Shh action in the neural tube and limb, as well as the distinct cellular organization of each target field (epithelial and mesenchymal, respectively), it is clear that Shh signaling acts directly over considerable distances, up to 30 cell diameters, or $300 \mu \mathrm{m}$.

\section{Generation, reception, and transduction of the Hh signal}

Not surprisingly given the advantages and history of unbiased genetic screens in Drosophila, our present knowledge about the generation and reception of Hedgehog signals derives primarily from genetic analysis in this organism. Simple cell culture systems have, however, also provided a valuable tool for addressing the mechanisms, especially of vertebrate Hh activities. For example, several cell lines, and primary embryo fibroblasts, show an up-regulation of Ptcl in response to Shh addition (Murone et al. 1999; Taipale et al. 2000). One of these lines, C3H10T1/2, has been particularly useful as these cells show a Shh-dependent activation of alkaline phosphatase (most likely reflecting osteoblast activity) that is easily quantified (Nakamura et al. 1997; Murone et al. 1999). These cells have facilitated structure/function analyses of distinct forms of Hh proteins, as well as the biochemical and cellular analysis of the signal transduction pathway. In what follows, we present a framework 
that is based largely on studies using flies or tissue culture cells, with some embellishment drawn from the analysis of vertebrate embryos.

\section{Hh biosynthesis and structure}

Hh family proteins are synthesized as $\sim 45-\mathrm{kD}$ precursor proteins that undergo an intramolecular cleavage (Lee et al. 1994; Bumcrot et al. 1995) that is catalyzed by the C-terminal portion of the precursor (Lee et al. 1994; Porter et al. 1995). This reaction yields a $25-\mathrm{kD}$ C-terminal fragment that has no other known function and an $\sim 19$. $\mathrm{kD} \mathrm{N}$-terminal fragment (referred to as $\mathrm{Hh}-\mathrm{N}$ ) that is sufficient for all known $\mathrm{Hh}$ signaling activity. Structural analysis of Hh-N provided initial excitement as it revealed a striking conservation with zinc hydrolases, suggesting that the Hh ligand might have an enzymatic activity (Hall et al. 1995). However, an absence of conservation of key histidines that coordinate the zinc ion in hydrolases and biochemical analyses in cell culture seem to argue against an enzymatic role for the signaling moiety (Fuse et al. 1999).

The autocleavage of $\mathrm{Hh}$ proceeds via a thioester intermediate that undergoes a nucleophilic attack by cholesterol, resulting in the covalent coupling of cholesterol to the $\mathrm{C}$ terminus of Hh- $\mathrm{N}$ to yield the processed form of the signaling moiety, denoted Hh-Np (Porter et al. 1996b). This unusual modification has attracted considerable interest in particular because it results in membrane retention of $\mathrm{Hh}$ proteins, a finding that appears at odds with their proposed long-range signaling activities (Lee et al. 1994; Bumcrot et al. 1995; Porter et al. 1995). This apparent paradox is discussed below.

In addition to cholesterol-coupling, analysis of Shh expressed in tissue culture cells has revealed a further lipid modification, palmitoylation of its most N-terminal cysteine (Pepinsky et al. 1998). This residue is highly conserved in all Hh proteins, suggesting that palmitoylation may be a universal feature, a view supported by the recent discovery that Drosophila Hh is similarly modified (Chamoun et al. 2001). Mutations of the sightless/skinny hedgehog (sig/ski) gene, which is specifically required in Hh-secreting cells for Hh function, have provided insights into the mechanism and role of Hh palmitoylation (Chamoun et al. 2001; Lee and Treisman 2001). The sig/ ski gene encodes a polytopic transmembrane protein with similarity to mammalian acyl transferases that catalyze O-linked acyl transfers. Because the linkage of palmitate to the $\mathrm{N}$ terminus of Shh- $\mathrm{Np}$ is via an amide bond, Chamoun et al. (2001) suggest that the modification may proceed via a thioester intermediate. Interestingly, Hh-N is rendered inactive in sig/ski mutants, implying that palmitoylation occurs independently of cholesterol modification. In contrast, studies of Shh modification in tissue culture cells suggest that palmitoylation is in some way dependent on cholesterol addition, as only a small fraction of a form of Shh-N that lacks cholesterol, generated by a mutant form of the cDNA, is palmitoylated (Pepinsky et al. 1998).

Although palmitoylation appears to be essential for the activity of the Drosophila protein, an un-acylable form of Shh retains some activity when expressed in transgenic Drosophila imaginal discs (Chamoun et al. 2001; Lee and Treisman 2001). In line with this, the unmodified form of Shh can elicit equivalent responses in some in vitro assays when administered at significantly higher concentrations $(20-30 \times)$ than mature native protein. In other contexts, however, notably the ventralization of neural plate explants, both acylated and unmodified forms of the protein appear to have equivalent or very similar levels of activity (Pepinsky et al. 1998; Kohtz et al. 2001). Replacement of the N-terminal Cys by a hydrophobic residue is itself sufficient to increase signaling activity, indicating that it is the hydrophobicity per se, rather than the specific nature of the palmitoyl moiety, that potentiates activity (Taylor et al. 2001).

In Drosophila embryos, $\mathrm{Hh}$ accumulates in characteristic membrane-associated patches (Taylor et al. 1993; Tabata and Kornberg 1994) that most likely correspond to lipid rafts (Rietveld et al. 1999), that is, membrane microdomains that function as platforms for intracellular sorting and signal transduction. The lipid modifications of Hh may play a role in targeting them to rafts; testing this proposition will require a comparison of the subcellular localization and trafficking of the modified and unmodified forms of the protein.

\section{Hedgehog reception}

Although it is now 10 years since the polytopic membrane-spanning protein encoded by the ptc gene was first hypothesized to act as the $\mathrm{Hh}$ receptor (Ingham et al. 1991), the mechanism of Hh reception remains a contentious issue. Intriguingly, Ptc belongs to a growing family of integral-membrane proteins that characteristically possess a so-called sterol-sensing domain (SSD), first identified in proteins implicated in cholesterol metabolism but now more broadly associated with vesicle trafficking. A single ptc gene is present in Drosophila, whereas vertebrates have two distantly related family members, Ptc1 and Ptc2 (Carpenter et al. 1998; Motoyama et al. 1998; Lewis et al. 1999a). Strikingly, although devoid of $h h$, the C. elegans genome contains two homologs of ptc as well as numerous ptc-related (ptc-r) genes (Kuwabara et al. 2000), including one that encodes CHE14, a protein implicated in apical sorting in epithelial cells (Michaux et al. 2000). Apart from the latter and the related Drosophila Dispatched (Disp) protein (of which more below; Burke et al. 1999), the closest eukaryotic relative of Ptc is the NPC1 protein, discovered through its association with Niemann-Pick syndrome, a disease of cholesterol storage/metabolism (see Fig. 4; Carstea et al. 1997; Loftus et al. 1997).

The analysis of Ptc mutations in Drosophila, mouse, and man has revealed that Ptc activity suppresses $\mathrm{Hh}$ target gene expression (Ingham et al. 1991; Capdevila et al. 1994a; Gailani et al. 1996; Dahmane et al. 1997; Goodrich et al. 1997), supporting the notion that Hh ligands elicit their effects by antagonizing Ptc activity (see Fig. 5 below). Evidence that this antagonism is accomplished 


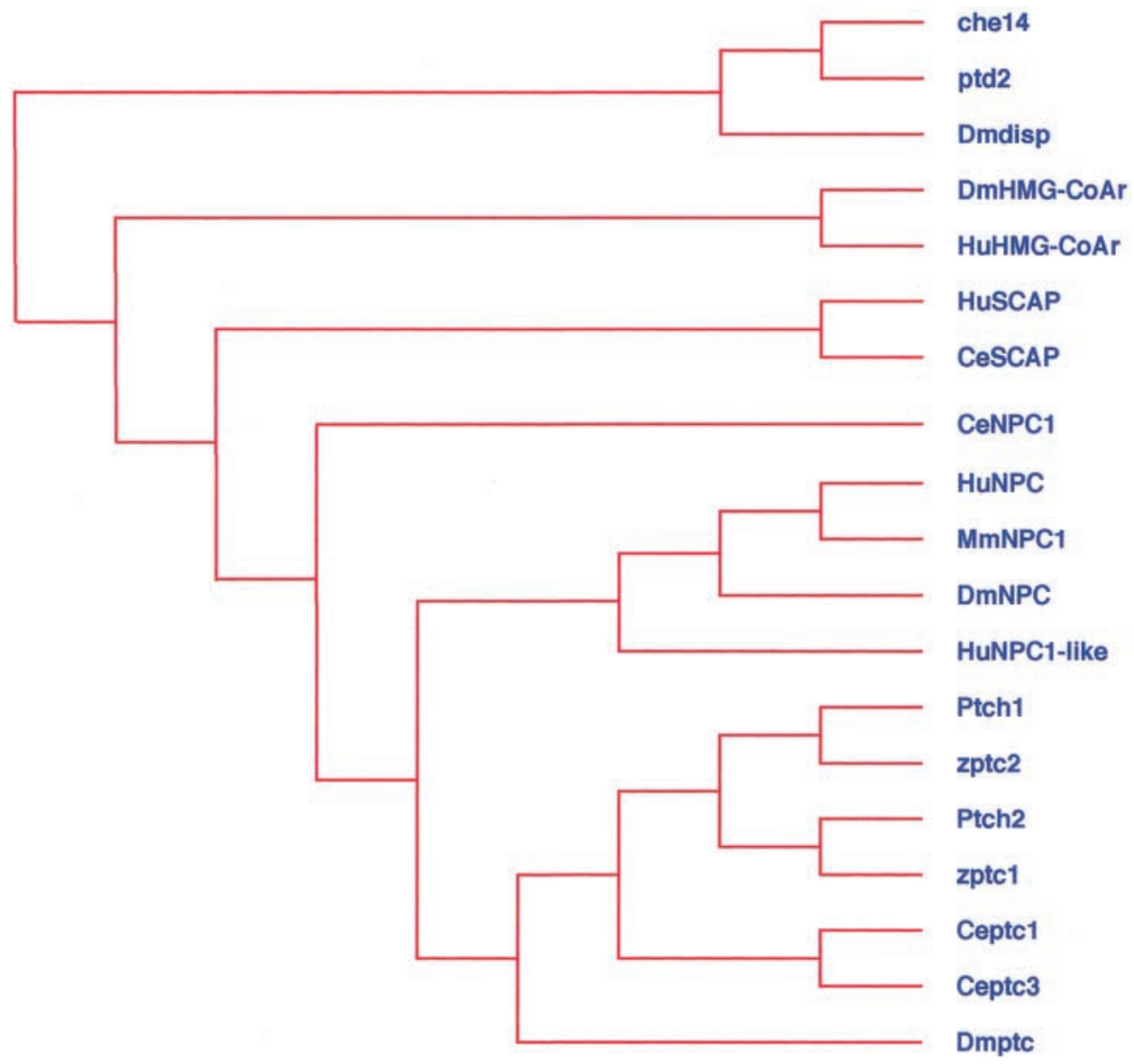

Figure 4. Phylogenetic relationship of sterol-sensing domain (SSD) proteins This comparison reveals the SSD domain of vertebrate and invertebrate Ptc proteins to be most closely related to that of the NPC1 protein and most distantly related to that of Disp despite the latter being the only other member of this family implicated in Hh signaling. (Ce) C. elegans; (z) zebrafish; (Hu) human; (Dm) Drosophila melanogaster; $(\mathrm{Mm})$ mouse.

by direct physical interaction between the proteins comes from two sources. Initially, in vitro studies established that Shh can bind to the large extracellular domains of Ptc1 when expressed in tissue culture cells or Xenopus oocytes (Marigo et al. 1996a; Stone et al. 1996; Fuse et al. 1999). Subsequently, in vivo studies have shown that mutation or deletion of the extracellular domains of Ptc or Ptcl reduces or abolishes the responsiveness of cells to Hh (Mullor and Guerrero 2000; Briscoe et al. 2001). Furthermore, Ptc and Hh are found to colocalize to intracellular vesicles in Hh-responding cells both in the Drosophila embryo and imaginal disc (Bellaiche et al. 1998; Burke et al. 1999; Martin et al. 2001; Strutt et al. 2001), suggesting that on binding to Ptc, the Hh-Ptc complex is internalized by responding cells. Support for a model of Ptc-mediated endocytosis as a conserved mechanism in the regulation of available ligand comes from studies in mammalian tissue culture that show soluble recombinant Shh protein can be internalized by cells transfected with the vertebrate Ptc1 gene (Incardona et al. 2000b). Once internalized, both proteins appear to be targeted to the lysosome, at least in some cell types (Mastronardi et al. 2000). Although the presence of an SSD in Ptc could imply a role for lipid moieties in facilitating ligand binding, mutation of the SSD does not appear to compromise either binding or internalization of Hh (Martin et al. 2001; Strutt et al. 2001). Moreover, in vitro assays indicate that neither cholesterol nor palmitoyl modification increases the affinity of Hh proteins for Ptc, although they do increase the specific activity of the protein (Pepinsky et al. 1998).

In both Drosophila and mammalian cells, the internalization of Ptc or Ptcl is dynamin-dependent, implying that it is mediated via clathrin-coated pits (Capdevila et al. 1994b; Incardona et al. 2000b). Although the finding that $\mathrm{Hh}$ accumulates in lipid rafts (Rietveld et al. 1999) would be consistent with an alternative mode of internalization, namely, via caveolae, it is not clear from these studies (which involved the fractionation of embryo extracts) whether the lipid raft accumulation represents protein in the sending or the receiving cell. Evidence that caveolae play some role in Ptc behavior comes from the reported association of the vertebrate Ptc1 protein with caveolin in tissue culture cells (Karpen et al. 2001). However, analysis of this system suggests a role for caveolin in the delivery of Ptc1 to the plasma 
membrane via lipid rafts rather than the internalization of a Shh/Ptc1 complex (Karpen et al. 2001).

The full significance of the formation and endocytosis of the Ptc-Hh complex can only be understood in the context of a third protein, Smoothened (Smo), the activity of which appears to be essential for all aspects of Hh signaling both in Drosophila (Alcedo et al. 1996; Chen and Struhl 1996; van den Heuvel and Ingham 1996) and vertebrates (Chen et al. 2001; Zhang et al. 2001). Smo belongs to the superfamily of G-protein-coupled receptor (GPCR) polytopic membrane-spanning proteins, being most closely related to the Frizzled family of Wnt receptors (Wodarz and Nusse 1998; Dann et al. 2001). In contrast to the latter, however, there is only limited evidence implicating heterotrimeric $\mathrm{G}$ proteins in Smo activity. In a classic assay for $\mathrm{G} \alpha_{i}$ activation, expression of human Smo in Xenopus melanophores appears sufficient to stimulate persistent pigment aggregation in these cells, an effect that can be blocked by pertussis toxin (DeCamp et al. 2000). In a primary fish myoblast assay system, however, the effects of Shh were found to be insensitive to pertussis toxin (Norris et al. 2000), and the results of treating zebrafish embryos with the toxin are inconclusive (Hammerschmidt and McMahon 1998). Notably, there is to date no report of a G-protein mutation that disrupts $\mathrm{Hh}$ signaling in Drosophila, despite several such mutations having been isolated (e.g., Wolfgang et al. 2001). Several missense mutations of various Smo proteins provide circumstantial support for G-protein coupling. The M2 mutation of human Smo, isolated from a spontaneously arising basal cell carcinoma, creates a constitutively active form of Smo. This results in an amino acid substitution in the seventh transmembrane domain predicted to disrupt G-protein coupling (Xie et al. 1998). A loss-of-function mutation in Drosophila Smo removes a charged residue in the third intracellular loop; similar mutations in GPCRs have been found to abolish G-protein coupling (S. Nystedt, $H$. Strutt, and P.W. Ingham, in prep.).

A second atypical feature of Smo is that unlike most
GPCR superfamily members, Smo appears not to interact directly with its activating signal. Instead, genetic epistasis analyses suggest that $\mathrm{Hh}$ binding to Ptc acts to abrogate an inhibitory effect exerted on Smo by Ptc (Hooper 1994; Chen and Struhl 1996; Quirk et al. 1997). The nature of this inhibitory interaction remains one of the central unsolved mysteries of $\mathrm{Hh}$ signaling. One model, based largely on analysis of the properties of the proteins when overexpressed in tissue culture cells (Stone et al. 1996; Murone et al. 1999), suggests that Smo and Ptc interact directly to form a membrane-associated receptor complex. The Smo present in this complex is postulated to be inactive in unstimulated cells, but, upon $\mathrm{Hh}$ binding to Ptc, the complex undergoes some conformational change that results in the activation of Smo (Fig. 5). It is notable, however, that in Drosophila, visualization of the two proteins suggests that most Smo does not colocalize with Ptc, at least in cells responding to Hh (Denef et al. 2000). Moreover, biochemical investigation of the postulated physical interaction between the two proteins in vivo has so far proved negative (Johnson et al. 2000).

Instead, studies in Drosophila have provided several interesting new insights into this enigmatic relationship. One key finding is that overexpression of Smo is not sufficient to activate the pathway, casting doubt on the proposed stoichiometric relationship between Ptc and Smo (Alcedo et al. 2000; Denef et al. 2000; Ingham et al. 2000). Strikingly, Smo protein accumulates specifically in cells in which Ptc activity is absent or abrogated by Hh signaling, a process that seems to involve the redistribution of a hyperphosphorylated form of the protein to the cell surface (Denef et al. 2000) and may also be accompanied by a conformational change (Ingham et al. 2000). How these changes in the stability, form, and distribution of the protein relate to one another and to the activity state of Smo is currently unclear. One attractive model, but by no means the only one, is that Hh binding to Ptc allows the trafficking of Smo to a specific membrane domain within the cell that facilitates its activa-
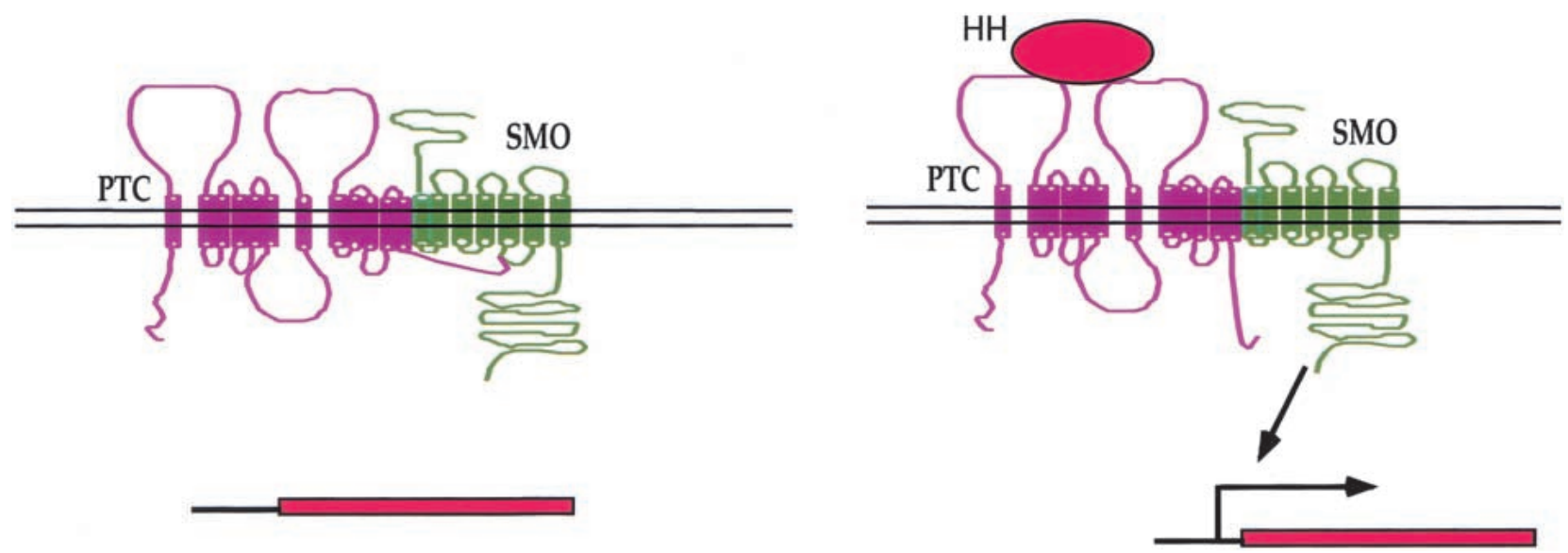

Figure 5. Conventional model of Hedgehog signal reception. Smo (green) has an intrinsic intracellular signaling activity that is repressed by its direct interaction with Ptc (red) within the plasma membrane. This repression is released when Hh binds to Ptc, with Smo undergoing a conformational change that allows it to activate its intracellular target(s). 
tion and hence transduction of the Hedgehog signal. That membrane trafficking plays a role in modulating signaling activity has received support from a surprising direction. Genetic screens in mice identified a mutation, open-brain $(o p b)$, that shows a phenotype opposite to that caused by loss of Shh activity (Gunther et al. 1994; Eggenschwiler and Anderson 2000). Significantly, floor plate and motor neurons, cell types that are absent in Shh mutants (Chiang et al. 1996), differentiate in embryos mutant for both $o p b$ and Shh, suggesting that the $o p b$ gene product acts downstream of Shh as a negative regulator of the pathway. Nevertheless, expression of some Shh target genes remains sensitive to Shh activity even in the absence of $o p b$ function, indicating that loss of $o p b$ does not result in complete derepression of the pathway (Eggenschwiler et al. 2001). Cloning of opb has revealed that it encodes $\mathrm{RAB} 23$, a member of a large family of small GTP-activated proteins associated with many dynamic aspects of membrane trafficking (Eggenschwiler et al. 2001). Could Ptc1 negatively regulate Smo activity through a RAB23-dependent trafficking process?

The possibility that Ptc might mediate a trafficking process has also been raised quite independently of the $o p b$ analysis, through the homology of Ptc with other SSD-containing proteins (Martin et al. 2001; Strutt et al. 2001). One precedent for such a role is provided by SCAP, a key regulatory factor in cholesterol metabolism and transport, which acts by chaperoning the SREBP transcription factor between the endoplasmic reticulum and the Golgi apparatus, where it undergoes a cleavage- mediated activation (DeBose-Boyd et al. 1999; Nohturfft et al. 1999). By analogy, Ptc might traffic Smo to an intracellular compartment where it would be targeted for degradation (Fig. 6). In the case of SCAP, this trafficking is regulated by SSD-dependent sensing of cholesterol levels in the membrane, point mutations in the SSD causing constitutive translocation of SREBP to the Golgi compartment (Hua et al. 1996). Intriguingly, an identical mutation in the SSD of Ptc results in the loss of its Smoinhibiting activity (Martin et al. 2001; Strutt et al. 2001). In contrast to SCAP, however, altering cholesterol levels within the cell by various means has a relatively minor influence on $\mathrm{Hh}$ signaling, suggesting that Ptc activity is not similarly modulated by membrane sterol levels (Incardona et al. 2000a). An alternative possibility is that the SSD serves to direct Ptc to a specific membrane microdomain where it inactivates Smo.

The activity of NPC1, an SSD-containing protein more closely related to Ptc, raises other possibilities. In the absence of NPC1, unesterified cholesterol accumulates in the late endosome compartment, which, in turn, disrupts sorting between the endosome and trans-Golgi network (Higgins et al. 1999; Kobayashi et al. 1999; Neufeld et al. 1999; Blanchette-Mackie 2000). This has led to the suggestion that NPC1 acts both as a sensor (through its SSD domain) and as a regulator of endosomal cholesterol content, with Ko et al. (2001) suggesting that NPC1 may cause vesicle budding by moving lipid molecules from one leaflet of the organellar membrane to the other. Recently it has been shown that NPC1 has weak similarity

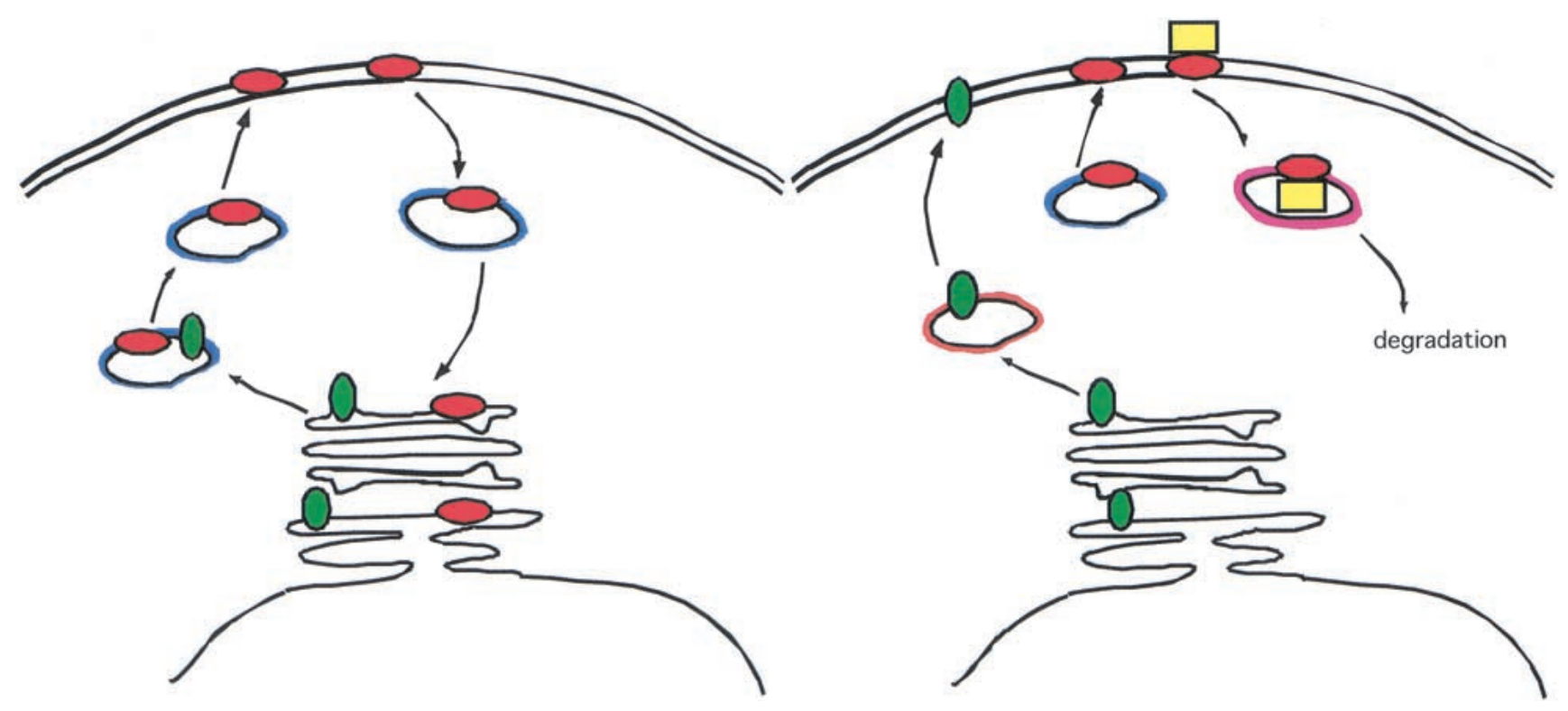

Figure 6. Unconventional-and highly speculative-model of Hh signaling Cells competent to receive the Hh signal (left) express both Smo (green) and Ptc (red). Ptc may mediate the sorting of Smo in the Golgi into a specific intracellular vesicle (blue) within which it is inactivated (and probably degraded). For simplicity, both proteins are shown to be sorted into the same vesicle, but this need not be the case. Ptc itself continues to the plasma membrane before being recycled to the Golgi (a process that might be dependent on Rab 23), where it again participates in Smo sorting. Exposure of cells to the Hh ligand (yellow), however, results in Ptc binding Hh when it reaches the plasma membrane: the bound receptor is then targeted to the lysosomal pathway (pink vesicle). The consequent decrease in the intracellular pool of Ptc is sufficient to allow Smo to enter a different trafficking pathway (orange vesicle), such that it is transported to the plasma membrane, where it engages with and activates intracellular signaling factors. 
to the RND family of prokaryotic permeases and, indeed, has permease activity in both eukaryotic and prokaryotic cells (Davies et al. 2000). In both cases, NPC1 can transport fatty acids across membranes. But although it is thus able to transport lipophilic molecules out of the endosome-lysosome system, it is not clear how this modulates cholesterol levels. Strikingly, Ptc is more closely related to the bacterial AcrB and MexD permeases than it is to NPC1, raising the possibility that it may also function as a permease.

Although Ptc is clearly a Hh receptor, recent evidence in Drosophila has indicated that Hh can in some circumstances signal to cells by a Ptc-independent mechanism (Ramirez-Weber et al. 2000). This raises the possibility that some other protein may control the activity of Smo in the absence of Ptc, but the identity of such a protein so far remains a mystery. In contrast to the fly, vertebrates have a second Ptc gene, Ptc2, the product of which could in principle also act as a Hedgehog receptor. Indeed, both Ptc1 and Ptc2 bind all mammalian Hedgehog proteins (Carpenter et al. 1998). In many tissues, however, Ptc2 is actually expressed in Hh-secreting cells, suggesting that either Ptc2 acts in an autocrine signaling loop, or has a function distinct from that of Ptcl. Direct binding studies have identified a second Shh-binding protein in vertebrates, Hedgehog-interacting protein (Hip1), a membrane-bound protein (Chuang and McMahon 1999). Hip1 binds all mammalian Hh proteins with an affinity similar to that of Ptc1, but this binding most likely regulates the availability of ligand, thereby attenuating signaling rather than activating a novel pathway (P. Chuang and A. McMahon, in prep.).

\section{Control of Hh secretion and distribution}

The roles of Hedgehog proteins as both short- and longrange signals imply the existence of mechanisms capable of regulating the release and movement of the proteins across cell assemblies. The discovery that $\mathrm{Hh}$ is covalently coupled to cholesterol immediately suggested a mechanism by which the action of the protein might be spatially restricted, such a lipid attachment being expected to anchor the protein in the membrane of secreting cells. Consistent with this, little $\mathrm{Hh}-\mathrm{Np}$ is found in medium conditioned by cells expressing the full-length protein (Pepinsky et al. 1998; Zeng et al. 2001). In contrast, cells expressing an unmodified form of Hh-N (generated by a C-terminally truncated form of the coding region, which circumvents the autoproteolysis and hence the cholesterol coupling step) secrete large quantities of this unmodified form, $\mathrm{Hh}-\mathrm{Nu}$, into the medium (Bumcrot et al. 1995; Porter et al. 1995). In line with these findings, expression of the $\mathrm{Hh}-\mathrm{Nu}$ in the embryonic ectoderm was found to have effects consistent with an increased range of Hh activity (Porter et al. 1996a).

Such cholesterol-mediated membrane anchoring could thus explain the restricted range of Hh in the Drosophila embryo and in certain contexts in vertebrate embryos (such as tooth and hair development), where Hh appears to act at short range, but it seems at odds with the long- range signaling activities of the protein in the limbs and neural tube. As discussed above, Hh proteins demonstrably traverse many cell diameters to elicit their effects in these contexts, implying that they must be released from the cells that secrete them. Intriguingly, genetic analysis in the fly has revealed that a Ptc-related protein, aptly named Dispatched (Disp), is specifically required for the controlled release of Hh-Np (Burke et al. 1999). In the absence of Disp function, Hh-expressing cells accumulate high levels of $\mathrm{Hh}$ but fail to secrete it; as a consequence, Hh target genes are not activated in responding cells. This requirement is completely overridden when $\mathrm{Hh}-\mathrm{Nu}$ is expressed in disp mutant cells (Burke et al. 1999), indicating that it is only needed for the secretion of the lipid-modified form of Hh-N (see Fig. 7). Interestingly, Disp is required in the embryonic ectoderm as well as in the posterior compartment of the imaginal disc (Burke et al. 1999), implying that the release of Hh$\mathrm{Np}$ is essential for both the long-range and short-range modes of Hh signaling.

How Disp functions remains unclear, although its possession of an SSD again suggests a role in vesicle trafficking. One possibility is that, like its C. elegans counterpart CHE14 (Michaux et al. 2000), Disp plays a role in apico-basal sorting of $\mathrm{Hh}$. In the embryonic ectoderm Hh has been shown to accumulate preferentially basolaterally (Taylor et al. 1993; Tabata and Kornberg 1994), but a role of Disp in this localization has not been tested. In the cells of the imaginal disc, in contrast, there is no obvious polarity in the Hh distribution. Instead, Burke et al. (1999) suggest that Disp acts in some way to displace Hh-Np from the lipid rafts to which it is targeted by its cholesterol moiety.

Although Disp function thus overrides the restraining effect of cholesterol on Hh-Np in secreting cells, it is clear that the lipid modification has major consequences for Hh-Np mobility once it is released from its source. This is exemplified by the dramatically different consequences of driving expression of full-length Hh versus $\mathrm{Hh}-\mathrm{Nu}$ in the posterior compartment of the wing imaginal disc. Whereas the former has little if any effect on the growth and patterning of the wing, the latter results in a massive expansion of the $d p p$ expression domain and the simultaneous overgrowth of the wing, effects consistent with the unrestrained movement or diffusion of $\mathrm{Hh}-\mathrm{Nu}$ across the anterior compartment (Burke et al. 1999). This implies that $\mathrm{Hh}-\mathrm{Np}$ is subject to some restraining influence on its movement once released from the secreting cells by activity, an influence that has been shown to be mediated by Ptc (see Fig. 7). In a series of elegant experiments in which they manipulated Ptc activity in clones of cells in the wing imaginal disc, Chen and Struhl (1996) showed that Hh-Np can freely traverse cells lacking the Hh-binding activity of Ptc, before being bound and endocytosed by the protein in genetically wild-type cells. This sequestering activity of Ptc helps explain why the ptc gene itself is a target of Hh activity: by up-regulating ptc transcription, Hh effectively promotes its own sequestration, a negative feedback mechanism that restrains the spread of $\mathrm{Hh}$ protein from its source /Chen 


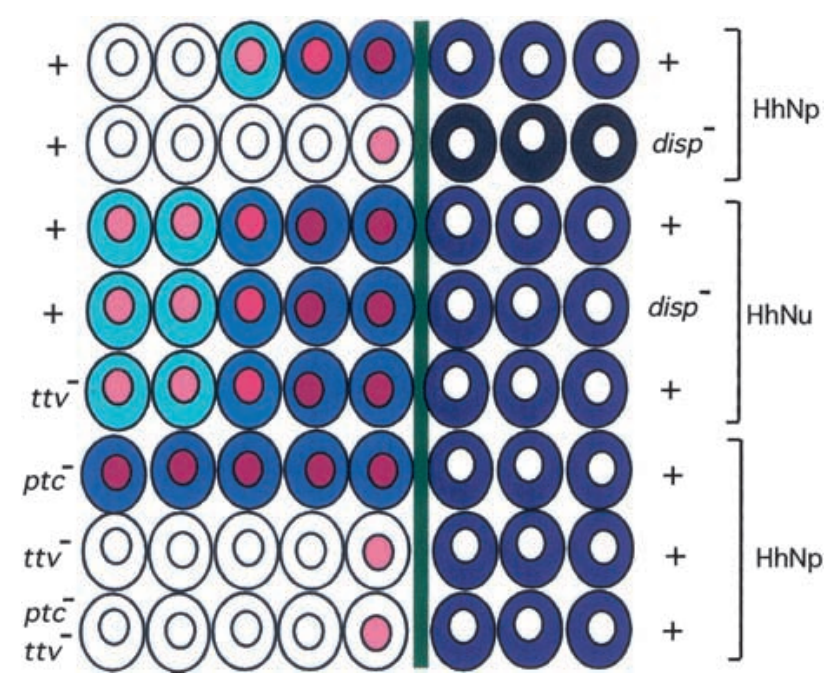

Figure 7. The control of Hh movement. Highly stylized representations of the distribution and activity of $\mathrm{Hh}-\mathrm{Np}$ or $\mathrm{Hh}-\mathrm{Nu}$ proteins in imaginal discs in the presence or absence of $\mathrm{Ptc}$, , or TTV functions. The top row of cells illustrates the decreasing concentration of Hh-Np protein (represented by different shades of blue) in anterior compartment cells as a function of distance from the compartment boundary (vertical green line). This graded $\mathrm{Hh}$ activity results in differential target gene activation (represented by varying shades of red in the nuclei). Cells in the posterior compartment express a uniform level of Hh- Np. In the absence of function (row 2), Hh-Np accumulates in expressing cells (dark blue shading) but fails to be secreted efficiently. Some target gene expression is seen in cells immediately adjacent to the compartment boundary, suggesting that a little Hh, below the level of detection, does escape despite the absence of Disp. Retention of Hh-Np in the absence of function is mediated by Disp the cholesterol moiety because $\mathrm{Hh}-\mathrm{Nu}$ is efficiently secreted by mutant cells (row 4). Whether or not Hh-Nu can maximally activate the pathway as indicated here has not been definitively established, although it has been shown to activate high levels of ptc transcription (Burke et al. 1999). It is clear, however, that $\mathrm{Hh}-\mathrm{Nu}$ is able to traverse many more cell diameters than Hh-Np (row 3), implying that the cholesterol also mediates the sequestration of $\mathrm{Hh}-\mathrm{Np}$ by receiving cells. Such sequestration depends on the presence of Ptc in receiving cells (row 6), as Hh-Np is able to traverse multiple ptc cells. Note that in this case, the activation of target gene expression is independent of $\mathrm{Hh}$ and is caused solely by the absence of the repressive activity of Ptc. Movement of Hh-Np depends absolutely on TTV function in receiving cells: In the absence of TTV (row 7), Hh-Np fails to move beyond the compartment boundary, even if Ptc protein is also absent (row 8). Note that cells immediately adjacent to the Hh-expressing cells show reduced levels of target gene activation, indicating that TTV activity is required even in these cells. This suggests that it may facilitate the release of $\mathrm{Hh}$ from neighboring cells as well as movement between receiving cells. In contrast, $\mathrm{Hh}-\mathrm{Nu}$ is able to traverse $t t v^{-}$cells (row 5), indicating that the requirement for TTV activity is imposed by the cholesterol moiety.

and Struhl 1996). That Hh-Nu appears immune to such sequestration implies that it depends critically on the cholesterol moiety in Hh-Np. Although this might suggest that cholesterol mediates interaction between Hh$\mathrm{Np}$ and Ptc, perhaps via the latter's SSD, several findings argue against this. Not least of these are the facts that $\mathrm{Hh}-\mathrm{Nu}$ efficiently activates the pathway by abrogating Ptc activity and that lipid modification has no significant effect on the in vitro binding affinity of Hh for Ptc. Moreover, Hh-Nu appears to be endocytosed with Ptc in responding cells (Burke et al. 1999), all of which raises questions about the basis of Hh sequestration.

Remarkably, whereas recent studies in chick embryos suggest that Ptcl has a similar role in sequestering Shh in the vertebrate neural tube (Briscoe et al. 2001), in vivo analysis of an unmodified form of Shh-N (Shh-Nu) reveals a quite different effect of cholesterol modification on its behavior (Lewis et al. 2001). In this case, absence of the cholesterol moiety severely limits the range of the Shh-Nu protein. Therefore, although it retains activity comparable to that of the wild-type protein at short range (as assayed by its ability to promote normal hair, whisker, tooth, and lung development and to promote the specification of the most posterior digits in the hand and foot plates), it fails to spread across the developing limb bud, leading to a contraction in the expression domains of target genes and an accompanying loss of intermediate digits (Lewis et al. 2001). These findings point, instead, to a requirement for cholesterol modification for the efficient movement of Shh-N through the limb mesenchyme, a requirement that seems at odds with the properties of the Hh-Nu form in Drosophila.

It is possible that this disparity may reflect a difference in the experimental conditions under which the unmodified forms of the respective proteins have been assayed, or in the cellular milieu in which the endogenous forms normally operate (Lewis et al. 2001), but it is also notable that in vertebrates, Hh proteins are subject to an additional restraining influence, namely, that imposed by Hipl (Chuang and McMahon 1999), an Hh-binding protein that has no counterpart in Drosophila. Like Ptc, expression of Hipl is up-regulated in response to Hh signaling (Chuang and McMahon 1999), but unlike Ptc, there is no evidence that it acts by directly regulating Smo. Therefore, Hipl adds a second layer of control to the Hh negative feedback mechanism, a layer that is exclusive to vertebrates.

One scenario that could reconcile the immunity of Drosophila $\mathrm{Hh}-\mathrm{Nu}$ to Ptc sequestration with the attenuated range of Shh-Nu in the mouse would be if Shh-Nu were to bind Hip with equal or greater affinity than its cholesterol-coupled counterpart. In this case, Shh-Nu would still be capable of antagonizing Ptc at short range, but would not be free to move beyond cells immediately adjacent to its source. But how might cholesterol coupling allow Shh-Np to override Hip sequestration?

In Drosophila, movement of the cholesterol-modified form of Hh-Np depends critically on the activity of tout velou (ttv) (see Fig. 7; Bellaiche et al. 1998), a homolog of the human EXT genes that were identified through their association with the bone disorder multiple exostoses (Stickens et al. 1996). These genes encode GAG transferases (Lind et al. 1998), implying that TTV (and its vertebrate homologs) generates a proteoglycan that mediates the transfer of Hh-Np between cells (Bellaiche et al. 
1998; Thé et al. 1999). That the activity of TTV is required in Hh-receiving cells even in the absence of Ptc (Bellaiche et al. 1998) implies that the hypothetical proteoglycan may interact directly with $\mathrm{Hh}-\mathrm{Np}$ and possibly present it to Ptc, a process similar to that proposed above for Hip. If both the proteoglycan and Hip compete for Hh-Np binding and if cholesterol coupling is obligate for interaction with the former, then it is easy to envisage how in vertebrates, the absence of cholesterol from Shh$\mathrm{Nu}$ would block its movement and lead to its sequestration by Hip. In Drosophila, in contrast, where there is no Hipl to bind unsequestered $\mathrm{Hh}-\mathrm{Nu}$, the latter might remain free simply to diffuse away from its source, abrogating Ptc activity in its wake. Investigating the properties of Shh-Nu in a Hip mutant background should therefore help to resolve this issue.

\section{Transduction to the nucleus: the control of Cubitus interruptus activity}

Although the biochemical nature of Smo activity remains a mystery, it is clear that a major target of this activity is the transcription factor encoded by the Drosophila segment-polarity gene cubitus interruptus (ci). Although genetic analysis identifying $\mathrm{Ci}$ as the mediator of Hh-dependent transcriptional activation was first presented more than eight years ago (Forbes et al. 1993), unraveling the molecular mechanisms that underlie the function of this complex protein is still far from complete. The task has been confounded by various factors, not least the rapid nuclear export of the active form of the protein, making it difficult to detect in situ, as well as by the fact that $\mathrm{Ci}$ combines both repressor and activator functions in a single protein, complicating the analysis of mutant phenotypes. Recent studies have, however, overcome both of these problems, and a fairly detailed picture of events downstream of Smoothened is now beginning to emerge.

One long-standing puzzle has been the disparity between the phenotypes caused by mutations of ci compared with those of hh mutants (see Methot and Basler 2001). This has led to the suggestion that Hh activity is not exclusively mediated by $\mathrm{Ci}$, a view supported by the analysis of $\mathrm{Hh}$ target gene expression in embryos lacking all Ci activity (Gallet et al. 2000). Another explanation for this disparity is suggested by the effects of loss of $\mathrm{Ci}$ function in the imaginal disc. Whereas removal of $\mathrm{Ci}$ activity from clones of cells was shown to result in the loss of expression of some Hh target genes, notably ptc (Dominguez et al. 1996), consistent with $\mathrm{Hh}$ activation of ptc transcription being mediated by Ci (Alexandre et al. 1996), other Hh targets, such as $d p p$, were found to be activated in the absence of $\mathrm{Ci}$, albeit at a lower level than in their normal domain close to the compartment border. This latter observation led to the idea that $\mathrm{Ci}$ is bifunctional, controlling the expression of $\mathrm{Hh}$ targets both by activation and repression. In this view, if $\mathrm{Hh}$ signaling acts by promoting an activating form and inhibiting a repressing form of $\mathrm{Ci}$, complete removal of the $\mathrm{Ci}$ protein should not be equivalent to loss of Hh signal- ing, but, rather, should result in a partial gain-of-function phenotype that is epistatic to an $h h$ loss-of-function mutation. Analysis of null alleles of $c i$ in combination with $h$ h mutations have confirmed this view, implying that all known functions of $\mathrm{Hh}$ in the Drosophila embryo and imaginal disc are, indeed, transduced by modulation of Ci activity (Methot and Basler 2001).

The repressor form of $\mathrm{Ci}(\mathrm{Ci} 75)$ is generated by a proteolytic cleavage event that removes the transcriptional activation domain of the protein, yielding a truncated protein that retains the zinc finger-binding domain and an N-terminal repression domain (Aza-Blanc et al. 1997). Crucially, although Ci75 is present in all Hh-responsive cells, the full-length form (Ci155) accumulates specifically in cells in close proximity to those secreting $\mathrm{Hh}$ (Motzny and Holmgren 1995; Aza-Blanc et al. 1997; Wang and Holmgren 1999), strongly suggesting that $\mathrm{Hh}$ acts by inhibiting its proteolytic cleavage. Such an inhibitory effect could provide the basis of a simple Hhmediated switch from transcriptional repression to activation, simply by stabilizing the full-length $\mathrm{Ci}$ protein (see Fig. 8).

Consistent with this model, cells lacking the activity of either Protein kinase A (PKA) (Johnson et al. 1995; Ohlmeyer and Kalderon 1998) or the novel kinesin-related protein Costal-2 (Cos-2) (G. Wang et al. 2000) accumulate full-length $\mathrm{Ci}$ independently of $\mathrm{Hh}$ activity and at the same time inappropriately activate $\mathrm{Hh}$ target genes. Cos-2 binds microtubules in an Hh-sensitive manner (Robbins et al. 1997) and forms a complex with $\mathrm{Ci}$ via a domain in its $\mathrm{C}$ terminus termed the CORD /G. Wang et al. 2000), suggesting that the cleavage of Ci depends on its being sequestered on microtubules. In this way, Hh-induced dissociation of the complex from the microtubules would suffice to inhibit Ci cleavage. Ci has several PKA consensus target sites, suggesting that PKA may act directly to facilitate cleavage of the protein, its phosphorylation either priming it for protease recognition or promoting its association with Cos-2 (but see below). Consistent with this view, mutation of one or more of the PKA sites in $\mathrm{Ci}$ is sufficient to inhibit its cleavage (Chen et al. 1998). Although it has been speculated that, by analogy with G-protein-coupled receptors, activation of Smo might modulate PKA activity (Alcedo et al. 1996), there is good evidence that Hh signaling has no effect on PKA activity (Jiang and Struhl 1995). Therefore, it seems that phosphorylation by PKA is permissive for $\mathrm{Ci}$ cleavage, the rate-limiting step being recruitment of $\mathrm{Ci}$ to the microtubules. However, Hh might also contribute to cleavage regulation by promoting the dephosphorylation of $\mathrm{Ci}$.

But is the inhibition of Ci cleavage sufficient to promote the transcriptional activation of Hh target genes? Two lines of evidence reveal that it is not. First, a form of Ci lacking the protease-recognition site, although resistant to cleavage, is totally inactive except in cells stimulated by Hh signaling (Methot and Basler 1999; G. Wang et al. 2000). Second, cells lacking the activity of the $\operatorname{simb}$ gene (which encodes an F-box protein implicated in priming substrates for proteasome-dependent 

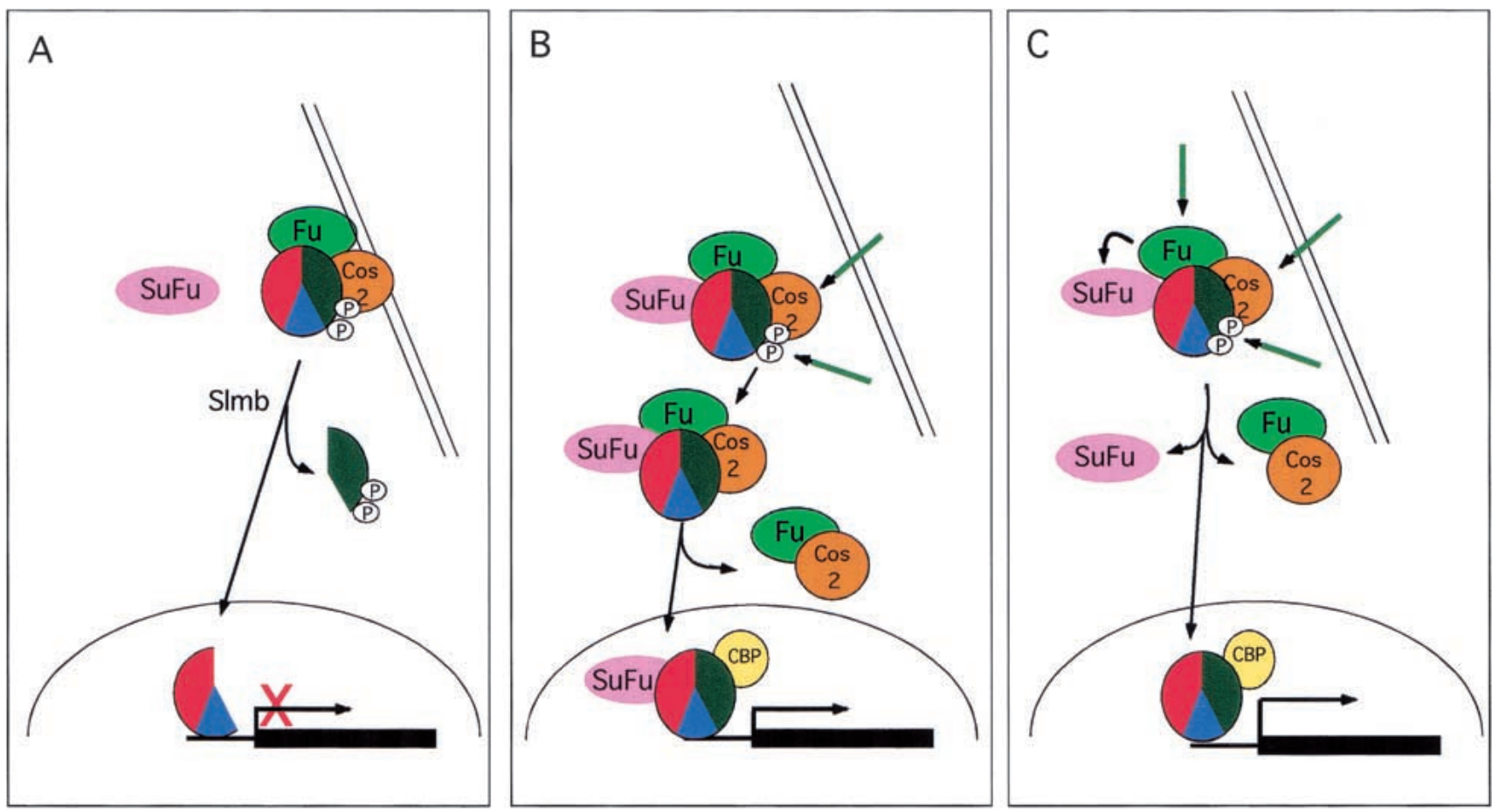

Figure 8. Intracellular transduction of the Hedgehog signal. In Drosophila, cells competent to respond to Hh express the transcription factor Ci. (A) In the absence of stimulation by the signal, full-length Ci (red, blue, and green sectored circle) is phosphorylated on several sites $(\mathrm{P})$ by PKA and anchored to microtubules (indicated by parallel lines) via its interaction with the Cos- 2 protein (orange oval) . Slmb-dependent cleavage of Ci C-terminal to its zinc finger domain (green sector) results in the release of a truncated form of the protein from microtubules and its accumulation in the nucleus, where it binds upstream of the Hh target gene $d p p$ as well as the hh gene itself, repressing transcription of both. $(B)$ Stimulation of cells by intermediate levels of Hh causes the dissociation (green arrow) of the Ci-Cos-2 complex from microtubules and the simultaneous inhibition of Ci cleavage. Full-length Ci binds to Su(fu) (pink oval) in the cytoplasm, an interaction that restricts its nuclear import and attenuates its transcription-activating activity. (C) Stimulation of cells by high levels of $\mathrm{Hh}$ additionally promotes the dephosphorylation (green arrow) of $\mathrm{Ci}$ and activates (green arrow) the Fu $\mathrm{S} / \mathrm{T}$ kinase (green oval), promoting dissociation of $\mathrm{Ci}$ from $\mathrm{Su}(\mathrm{fu})$ and stimulating its import into the nucleus, where it activates target genes such as $\mathrm{Col}$ and $e n$ in association with the coactivator CBP (yellow circle).

cleavage) accumulate full-length $\mathrm{Ci}$, but fail to activate ptc transcription (G. Wang et al. 2000). Taken together, these data indicate that the activity of the uncleaved form of $\mathrm{Ci}$ requires additional Hh-dependent regulation.

Because the full-length protein that accumulates in the absence of both Cos-2 and PKA activity is, in contrast, active, these two proteins must have additional repressive effects on $\mathrm{Ci}$ activity that are presumably abrogated by Hh signaling. In line with this interpretation, mutation of the PKA sites in Ci not only renders it uncleavable but also makes it constitutively active /Chen et al. 1999; Methot and Basler 1999; Price and Kalderon 1999|, yet, on the other hand, overexpression of Cos-2 is able to suppress the Hh-dependent activity of the uncleavable form of Ci (G. Wang et al. 2000). Given its apparent role in sequestering $\mathrm{Ci}$ in the cytoplasm, one obvious interpretation of these data is that Cos- 2 acts to prevent the nuclear import of $\mathrm{Ci}_{\text {; }}$ indeed, when the rapid nuclear export of $\mathrm{Ci}$ is blocked using Leptomycin $\mathrm{B}$, fulllength $\mathrm{Ci}$ is seen to accumulate at high levels in the nuclei of cells lacking Cos-2 activity (G. Wang et al. 2000). However, such unrestrained nuclear import does not seem to occur when PKA is inactivated, suggesting that phosphorylation of $\mathrm{Ci}$ is not essential for its sequestration by Cos-2 (Wang and Holmgren 2000).

So why should the inhibition of phosphorylation be sufficient to activate the protein? One suggestion is that the levels of uncleaved protein that accumulate in the absence of PKA activity overwhelm the sequestration mechanism, so that some uncleaved protein is able to enter the nucleus (Wang and Holmgren 2000). Paradoxically, however, the response of cells to loss of PKA (as assayed by the activation of $\mathrm{Hh}$ target genes) is stronger than that when Cos-2 activity is removed (Ohlmeyer and Kalderon 1998; G. Wang et al. 2000). This implies that phosphorylation has an additional effect on Ci, not only priming the protein for cleavage but also attenuating its activity, an effect that could be abrogated by the activity of an Hh-regulated phosphatase. Presumably in the absence of Cos-2, the full-length Ci remains phosphorylated on these critical residues (although this has not been established) and hence is not fully active.

It follows from all of this that Hedgehog can elicit multiple transcriptional outputs simply by modulating the effects of Cos-2 and PKA on the processing and nuclear import of $\mathrm{Ci}$. The fact that neither elimination of 
Cos-2 nor elimination of PKA alone can fully recapitulate the effects of unrestrained Hh signaling could most simply be explained by their parallel roles in repressing Ci155 activity, although this has yet to be tested by simultaneously removing both proteins from the same cells. Significantly, however, the effects of cos-2 and pka mutations can be enhanced by eliminating a third protein, Suppressor of fused $\mathrm{Su}(\mathrm{fu})$, a fact that reveals an additional level of complexity in the control of $\mathrm{Ci}$ activity. Although $\mathrm{Su}(\mathrm{fu})$ is itself completely dispensable-animals homozygous for a deletion of the gene are fully viable and fertile (Préat 1992) - the consequences of its absence on the effects of inactivating Cos-2 or PKA are quite dramatic. In both cases, Ci becomes maximally activated, as evidenced by the induction of en expression, but apparently for different reasons. In the absence of $\mathrm{Su}(\mathrm{fu})$ protein, inhibiting the PKA-dependent phosphorylation of Ci now results in the nuclear import of full-length $\mathrm{Ci}$ (Methot and Basler 2000), implying that $\mathrm{Su}(\mathrm{fu})$ also acts to retain $\mathrm{Ci}$ in the cytoplasm. Su(fu) has been shown to bind directly to the $\mathrm{N}$-terminal region of $\mathrm{Ci}$ in yeast two-hybrid assays (Monnier et al. 1998), but biochemical characterization of the proteins in vivo suggest that this interaction results in the formation of a complex distinct from that associated with microtubules (Stegman et al. 2000). This implies that $\mathrm{Su}(\mathrm{fu})$ may act in concert with Cos-2 to sequester $\mathrm{Ci}$ in the cytoplasm after it has been released from microtubules (Fig. 8).

Why, then, should removal of $\mathrm{Su}(\mathrm{fu})$ also potentiate the effects of removing Cos-2? One explanation could be that $\mathrm{Su}(\mathrm{fu})$ can enter the nucleus bound to $\mathrm{Ci}$ and attenuate its transcription-activating activity, a view supported by the properties of the vertebrate $\mathrm{Su}(\mathrm{fu})$ ortholog (Kogerman et al. 1999). Both of these functions imply that eliciting the maximal response of cells to Hh signaling requires the dissociation of $\mathrm{Ci}$ from $\mathrm{Su}(\mathrm{fu})$. This dissociation appears to be mediated by the fourth intracellular component of the pathway identified by genetic analysis in Drosophila, the product of the fused gene. fused encodes a serine-threonine $(\mathrm{S} / \mathrm{T})$ kinase, the activity of which is necessary for some but not all levels of response to Hh (Fig. 8; Alves et al. 1998; Ohlmeyer and Kalderon 1998; Therond et al. 1999). Therefore, both in the embryo and in the imaginal disc, transcriptional responses requiring low or intermediate levels of $\mathrm{Hh}$ activity are unaffected by the loss of Fused activity, whereas the maximal response (the expression of $w g$ in the embryo or col and en in the imaginal disc) is reduced or lost. Although no targets of Fused have been identified at the biochemical level, and, indeed, there is no biochemical evidence that Fused has S/T kinase activity, an attractive model is that Fused phospohorylates $\mathrm{Su}(\mathrm{fu})$, leading to its dissociation from Ci. This would increase the levels of $\mathrm{Ci}$ activity by simultaneously releasing it from the inhibitory effects of $\mathrm{Su}(\mathrm{fu})$ and promoting its entry into the nucleus. Consistent with this model, high levels of fulllength $\mathrm{Ci}$ are seen to accumulate in the cytoplasm of Hh-responding cells that lack Fused activity (Ohlmeyer and Kalderon 1998).
Gli proteins mediate transcriptional control by Hedgehog signaling in vertebrates

In contrast to the fly, vertebrates have not one but three Ci-related proteins, designated Gli1, Gli2, and Gli3 (after glioblastoma), all of which have been implicated in mediating the activities of the various $\mathrm{Hh}$ proteins. The situation in vertebrates is further complicated by the fact that the genes encoding at least two of these, Glil and Gli3, are themselves transcriptional targets of Hh signaling: Gli1 is activated and Gli3 repressed in response to Hh signals (Marigo et al. 1996b; Lee et al. 1997). As usual, genetics has been a powerful tool in addressing the activities of these proteins, although as in the fly, the complexity of Gli function has complicated the interpretation of such analyses. Thus, for instance, although studies of mutant combinations in the mouse have shown genetic interactions between Gli1 and Gli2 in the diencephalic region of the brain (Park and Bai 2000), Gli2 and Gli3 in skeletal development (Mo et al. 1997), Gli1 and Gli2, and Gli2 and Gli3 in lung development (Motoyama and Liu 1998; Park and Bai 2000), and Gli2 and Gli3 in tooth development (Hardcastle et al. 1998), the mechanistic action of the different Gli proteins in each of these organs remains unclear.

Such mutant analyses have been complemented by studies in cell culture. Interpretation of these data, however, is also problematic, not least because in several cases, cells that are not responsive to $\mathrm{Hh}$ signals have been used, whereas in other instances, the experiments have not addressed the response of Gli proteins to the presence or absence of $\mathrm{Hh}$ ligand. Given the many levels of posttranscriptional regulation of Ci activity, in particular the Hh-dependent suppression of cleavage that alters the balance between repressor (cleaved) and activator (uncleaved) forms, conclusions from these experiments should be treated with some caution. These studies have included the generation of modified forms of Gli proteins that reveal potent activities. N-terminal truncation of both Gli2 and Gli3, for example, generates strong activating forms of these proteins (Dai et al. 1999; Sasaki et al. 1999|, but because of the paucity of antibodies against the endogenous proteins, the in vivo relevance of these truncated forms remains unclear.

One novel approach that has been used to investigate the regulation of Gli protein activities and their relative contributions to transducing Hh signals, has been to express each in Drosophila imaginal discs (von Mering and Basler 1999; Aza-Blanc et al. 2000). Although a heterologous system, the genetics of this system can be rigorously controlled to a degree impossible in vertebrates, and the activities of each protein can be compared with the known activities of $\mathrm{Ci}$. These studies have led to the following predictions: (1) Gli1 and Gli2 are Hh-dependent activators of Hh targets; (2) Gli2 is also an Hh-independent repressor; (3) Gli3 is an Hh-dependent repressor; and (4) similar to Ci, proteolytic cleavage of Gli2 and Gli3 generates repressor forms of each protein. To what extent do these predictions match up to data in vertebrate systems? 
Notwithstanding the caveats noted above, there is overwhelming evidence in support of a role for Glil as an activator of $\mathrm{Hh}$ target gene transcription, although whether or not this activity is regulated directly by $\mathrm{Hh}$ signaling in vivo is not so clear. Overexpression of Gli1 in tissue culture cells or transgenic embryos can induce transcription of $\mathrm{Hh}$ target genes in the absence of $\mathrm{Hh}$ activity (Hynes et al. 1997; Sasaki et al. 1997; Ruiz i Altaba 1998, 1999), but unlike Ci, Gli1 does not appear to undergo proteolytic cleavage and does not bind to or require CBP for its activating function (Dai et al. 1999). Moreover, again in contrast to $\mathrm{Ci}$, transcription of Glil is under $\mathrm{Hh}$ control; indeed, up-regulation of Gli1, like Ptc1, is diagnostic of Hh signaling within a target field. The fact that Glil is activated in response to an Hh signal strongly implies that Glil is not the initial transducer of the $\mathrm{Hh}$ signal. Indeed, mutants that lack the zinc finger domain and show no activating capacity are homozygous viable, fertile, and show no characteristic Hh phenotypes (Park and Bai 2000). Nevertheless, evidence from studies in flies and in tissue culture suggest that Glil activity can be potentiated by $\mathrm{Hh}$ signaling (Dai et al. 1999); consistent with this suggestion, Gli1 has been shown to interact directly with the vertebrate $\mathrm{Su}(\mathrm{fu})$ protein, an association that can inhibit its nuclear import and abrogate its ability to activate transcription (Ding et al. 1999; Kogerman et al. 1999).

Full-length Gli2 can also activate transcription of $\mathrm{Hh}$ target genes in vertebrate tissue culture cells, but in this case the activation depends on Hh stimulation. This requirement can be overridden by deletion of the N-terminal domain of the protein, which turns Gli2 into a strong constitutive activator capable of inducing normally Shhdependent cell types when expressed in the mammalian brain (Sasaki et al. 1999). This apparent negative regulatory domain of the protein corresponds to the region of $\mathrm{Ci}$ that mediates the interaction with $\mathrm{Su}(\mathrm{fu})$. Direct evidence for an interaction between Gli2 and the vertebrate $\mathrm{Su}(\mathrm{fu})$ has not been presented, nor is there any evidence for an in vivo cleavage of the N-terminal region of Gli2; however, the activity and nuclear import of Gli2 is reportedly stimulated by the human Fused homolog (Murone et al. 2000), which presumably could act by abrogating the inhibitory effect of $\mathrm{Su}(\mathrm{fu})$.

In vivo evidence for an activating role of Gli2 comes from mouse mutants lacking the zinc finger regions (Ding et al. 1998; Matise et al. 1998). Absence of Gli2 leads to a complete loss of floor plate and a reduction in V3 interneurons, cell types that are dependent on high levels of Shh activity for their specification. Therefore, Gli2 appears to play a critical role in mediating the activity of Shh in the ventral neural tube (see Fig. 3). Furthermore, transcription of both Ptc1 and Gli1 is downregulated, consistent with Gli2 activation of these targets.

Whether or not Gli2 also has repressing activity is less certain. In contrast to Gli1, the Gli2 protein has been shown to undergo cleavage when expressed in tissue culture cells (Ruiz i Altaba 1999) as well as in transgenic Drosophila, but unlike $\mathrm{Ci}$, this cleavage appears to be insensitive to Hh activity, and the cleaved form represents only a minor fraction of the protein. Nevertheless, an artificially C-terminally truncated form of Gli2 can efficiently repress transcription of a Gli-reporter gene (Sasaki et al. 1999). Another line of evidence consistent with a repressive activity of Gli2 comes from mutations in the zebrafish gene that give rise to C-terminally truncated forms of the protein (Karlstrom et al. 1999). These mutants have weak dominant loss-of-Hh-function effects on somite patterning (van Eeden et al. 1996), consistent with the mutant proteins acting as repressors of Hh target genes. In the absence of a protein null allele, however, it remains unclear whether or not this reflects an activity of the endogenous Gli2 protein. Ectopic expression of Gli2 in Xenopus embryos has been reported to lead to a repression of Gli1-mediated floor plate induction, also consistent with Gli2 playing a repressive role (Ruiz i Altaba 1998). Yet this activity is hard to reconcile with the absolute requirement for Gli2 in induction of the floor plate revealed by loss of Gli2 function in the mouse. Although these results may reveal some interesting species-specific difference in the role of Gli2, they may equally well illustrate the potential pitfalls when making inferences about gene function solely on the basis of ectopic expression experiments. In the wild-type neural tube, Gli2 is present in cells responding to Shh input that could modify its activity, whereas there is no Shh input accompanying the ectopic expression of Gli2 in the Xenopus studies.

In contrast to Gli1 and Gli2, there is little doubt that Gli3 acts as a repressor of Hh targets as well as of Shh itself (Masuya et al. 1995; Ruiz i Altaba 1998); partial loss of this repressor activity most likely underlies the various skeletal anomalies associated with Gli3 mutations in the human population (for review, see Villavicencio et al. 2000). Repression of Hh targets both in cell culture and in the embryo (Dai et al. 1999; B. Wang et al. 2000) appears to be mediated by proteolytic cleavage of full-length Gli3 into a repressor form (the reported size of which varies between 83 and $100 \mathrm{kD}$ ) that lacks amino acids C-terminal to the zinc finger domains. This form accumulates preferentially in the nucleus of expressing cells (Dai et al. 1999; B. Wang et al. 2000). Although Gli3 lacks an obvious CORD and no vertebrate Costal-2 ortholog has yet been identified, the finding that it undergoes the same Hh-dependent cleavage when expressed in Drosophila strongly suggests that Gli3 processing occurs by a mechanism analogous to that controlling $\mathrm{Ci}$. In addition, Gli3 is itself a target of transcriptional repression by Shh (Marigo et al. 1996b).

Although some assays indicate an exclusively repressing activity of Gli3 (Sasaki et al. 1999; B. Wang et al. 2000), others have revealed evidence of an activating activity. For example, Gli3 activates a Gli1 promoter in an Shh-dependent mechanism in cell culture, and activation is further potentiated by association with CBP (Dai et al. 1999). Consistent with this, Gli3 has been shown to interact directly with the vertebrate $\mathrm{Su}(\mathrm{fu})$ protein (Pearse et al. 1999), as well as with a human homolog of Fused (Murone et al. 2000), as would be expected if the 
nuclear import of an activating form of Gli3 is regulated by Sh. Given that Gli3 is initially present within the embryo prior to production of an Hh signal, such an activating form of Gli3 could play a role in the initial activation of Hh targets such as Glil. Consistent with this view, Glil expression is greatly diminished in Gli3/Shh compound mutants (Litingtung and Chiang 2000). In contrast, Ptc1 expression is significantly up-regulated, which raises the possibility that different promoters in the same cells may respond differently to Gli3 input. The continued presence of Gli2 in these experiments further complicates their interpretation.

The general picture that emerges from these studies is one in which the different Gli proteins execute subsets of the functions that in Drosophila are subsumed by Ci. In the neural tube, a Gli2 activator function correlates with cells that require the highest levels of Shh signal. Gli1/Gli2 compound mutants are reported to have a similar phenotype to Gli2 mutants (Park and Bai 2000). Therefore, Gli2 plays the major role at spinal cord levels although some patchy loss of floor plate cells is observed in Glil mutants heterozygous for a Gli2 mutation, indicating that a Glil activator may play a minor role (Park and Bai 2000). The nature of the activated form of Gli2 in cells exposed to high levels of Shh remains unclear. Studies in Drosophila suggest that Gli2 is not subject to an Hh-dependent inhibition of cleavage (Aza-Blanc et al. 2000); by analogy with the other levels of Ci regulation, however, it seems likely that the phosphorylation state and/or nuclear import of Gli2 may be regulated by Shh. Notably, whereas floor plate fails to form and V3 interneurons are reduced in number in the absence of Gli2 activity, other Shh-dependent ventral cell types are unaffected, although their position changes because of the absence of midline cells. On the other hand, specification of these same Gli2-independent cell types (V2 interneurons and motor neurons--but not of floor plate cells-can be restored in Shh mutant embryos by the removal of Gli3 activity (Litingtung and Chiang 2000). Therefore, Gli3 appears to act in an opposite manner to Gli2, antagonizing the ventralizing activity of Shh presumably by repressing Shh targets, much as $\mathrm{Ci}$ acts to repress $d p p$ expression in the anterior compartment of the wing imaginal disc (see Fig. 3). These data do not exclude the possibility that activator forms of Gli3 may also play some role. For example, there are no data ruling out an activator form of Gli3 acting together with Gli2 to specify floor plate identity. It should also be noted that Glis may not be the exclusive mediators of Shh signaling in the ventral neural tube. For example, there is evidence that expression of COUPTFII in motor neurons is Shhdependent, but no consensus Gli-binding site is present within its regulatory region (Krishnan et al. 1997).

In the limb, in contrast, the effects of Shh may be mediated exclusively by Gli3. Gli1/Gli2 compound mutants have normal digit number and pattern, whereas Gli3 homozygous mutants show a dramatic polydactylous phenotype (Hui and Joyner 1993), consistent with Gli3-mediated repression as an important regulator of digit number. A key finding is the demonstration of a gradient of Gli3 processing across the limb bud (B. Wang et al. 2000). The ratio of full-length Gli3 to its processed repressor form decreases from posterior to anterior. In addition, there is an increase in the overall levels of protein that presumably reflects the inverse transcriptional gradient that forms in response to long-range Shh signaling. Therefore, one could imagine two simple models to explain the patterning activity of Gli3 in response to a Shh gradient: cells may either sense the absolute levels of Gli3 repressor, or alternatively the ratio of repressor to activator forms (assuming the full-length protein has activating activity), as proposed for Ci (von Mering and Basler 1999).

What is not known is whether this phenotype is completely independent of Shh signaling. Ectopic activation of Shh at the anterior margin is observed in mice heterozygous for Gli3 mutations (Masuya et al. 1995; Buscher et al. 1997); presumably this is also true in homozygous mutants, but this has not been reported. If so, this leaves open the possibility that ectopic Shh signaling could act positively through Gli2. Analysis of Gli3/Shh and Gli2/ Gli3 compound mutants would be informative.

\section{Concluding remarks}

The last decade has seen extraordinary progress in deciphering the roles and mechanisms of action of Hedgehog proteins. From models in the early 1990s of a short-range signal regulating pattern in the ectoderm of the Drosophila embryo, Hh proteins are now recognized as acting both locally and at long range to regulate a plethora of processes in vertebrate as well as invertebrate development. At every step in the unraveling of the signaling pathway there have been surprises, a fact that bears ample testimony to the power of genetic analysis in uncovering novel paradigms and principles. The first of these is the unusual autoprocessing that generates the active Hh ligands, a process that simultaneously couples them to cholesterol. As we have discussed above, this unique lipid modification contributes to some key properties of the Hh signal, mediating its controlled release and movement from its source. The process of cell-tocell transport depends on two other components that appear to be dedicated to Hh signaling: Dispatch-mediated release of Hh-Np from the sending cell and Toutvelu-dependent trafficking across the target field.

Cholesterol coupling may also ensure that Hh ligands are concentrated in membranes, increasing the likelihood of ligand/receptor interaction. Furthermore, the cholesterol anchor may target $\mathrm{Hh}$ ligands to membrane subdomains that also localize Ptc or Hip1, thereby facilitating either signaling or its termination by ligand sequestration. Robust negative-feedback mechanisms are a hallmark of most signaling pathways, and it is clear that in both the fly and the mouse, effective sequestration of Hh by Ptc is dependent on its cholesterol linkage. A second lipid modification, palmitoylation of the $\mathrm{N}$ terminus, also plays a key role, but most likely not in membrane retention or movement. Rather, increasing the overall hydrophobicity of this part of the protein some- 
how enhances its ability to inactivate Ptc. Determining the structural basis of this effect will be of key importance in understanding the dose-dependent effects of $\mathrm{Hh}$ ligands.

A further distinguishing feature of the Hedgehog pathway is its mechanism of receptor-mediated activation. In most cases, extracellular signals elicit their effects by binding to and activating a membrane-anchored receptor that, in turn, activates intracellular components of the pathway. Hh proteins, in contrast, act by repressing their receptor, Ptc, which, in turn, controls the expression of Hh target genes by repressing the activity of Smo. What is the logic of this unusual mechanism? Presently the answer is unclear, but most likely it relates to the peculiarities of Smo activation through some Ptc-dependent intracellular trafficking process, a feature that Ptc might share with SCAP, another SSD-containing regulatory factor. The recent discovery of the RAB protein encoded by the $o p b$ gene apparently dedicated to this process, strengthens this view. Future analysis of the subcellular behavior of Ptc and Smo should yield some important new insights into this enigmatic process.

Finally, we have described the unusual way in which Hh signaling elicits its effects at the transcriptional level by altering the sign of a bifunctional transcriptional regulator. In Drosophila, the absence of Hh ligand allows the cleavage of the Ci protein, converting it to a repressor form that can bind target genes to block their transcription. Derepression of Smo, in contrast, inhibits this cleavage and promotes the nuclear import of activated full-length $\mathrm{Ci}$, leading to the transcription of $\mathrm{Hh}$ target genes. This highly economic process is further exemplified by the finding that most, if not all, Hh signaling is mediated through Ci in Drosophila. Why, then, do vertebrates use three distinct Gli proteins as transcriptional effectors? One simple explanation could be that each operates similarly, but that gene duplication and the acquisition of new regulatory motifs have led to new tissues that incorporate Hedgehog signaling. Yet neither the expression patterns nor the activities of the different Gli proteins suggest this to be the case. Rather, there appears to have been a partial separation of repressor and activator activities into individual Gli proteins. At least one advantage of this elaboration would be to allow more complex responses within a target field; thus, the response of cells to Hh signaling would be dependent not only on the levels of ligand to which they are exposed but also on the particular repertoire of Gli genes that they express. Further analysis of the in vivo regulation of Gli proteins and of their binding specificities for different Hedgehog targets should help illuminate this aspect of the pathway.

It is striking that so much of what is known about this fascinating signaling mechanism to date has been gleaned from genetic analysis, be it in flies or mice. Yet whereas genetics has provided an elaborate framework for our understanding, future progress will require a concerted effort to dissect the signaling process at the biochemical and cell biological levels. The great advances that have been made in identifying Hh-dependent pro- cesses and describing the consequences of their activities must now be matched by elucidating the ways in which Hh activities elicit these different cellular responses. Characterization of the multimeric complex that regulates $\mathrm{Ci}$ activity has provided a solid basis for this analysis, but many questions remain, not least how Ptc and Smo interact and how Hh binding modulates their interaction. The coming years promise to be at least as revealing as the last.

\section{Acknowledgments}

We gratefully acknowledge the following for kindly providing material for some of the figures: A.-G. Borycki (Fig. 2), A. Jacinto (Figs. 1A and 3C), S. Roy and F. Muller (Fig. 3D), J. Briscoe (Fig. 3F), and Y. Nakano (Fig. 4). Our own research on Hedgehog signaling is supported by a Wellcome Trust Programme Grant 051824/Z/97 to P.W.I. and by an NIH grant NS 33642 to A.P.M.

\section{References}

Agarwala, S., Sanders, T., and Ragsdale, C. 2001. Sonic hedgehog control of size and shape in midbrain pattern formation. Science 291: 2147-2150.

Ahlgren, S. and Bronner-Fraser, M. 1999. Inhibition of sonic hedgehog signaling in vivo results in craniofacial neural crest cell death. Curr. Biol. 9: 1304-1314.

Alcedo, J., Ayzenzon, M., Vonohlen, T., Noll, M., and Hooper, J. 1996. The Drosophila smoothened gene encodes a 7-pass membrane-protein, a putative receptor for the hedgehog signal. Cell 86: 221-232.

Alcedo, J., Zou, Y., and Noll, M. 2000. Post-transcriptional regulation of smoothened is part of a self-correcting mechanism in the Hedgehog signaling system. Mol. Cell 6: 457-465.

Alexandre, C., Jacinto, A., and Ingham, P. 1996. Transcriptional activation of Hedgehog target genes in Drosophila is mediated directly by the Cubitus interruptus protein, a member of the GLI family of zinc finger DNA-binding proteins. Genes \& Dev. 10: 2003-2013.

Alexandre, C., Lecourtois, M., and Vincent, J.-P. 1999. Wingless and Hedgehog pattern Drosophila denticle belts by regulating the production of short-range signals. Development 126: 5689-5698.

Alves, G., Limbourg-Bouchon, B., Tricoire, H., Brissard-Zahraoui, J., Lamour-Isnard, C., and Busson, D. 1998. Modulation of Hedgehog target gene expression by the fused serinethreonine kinase in wing imaginal discs. Mech. Dev. 78: 1731.

Aspock, G., Kagoshima, H., Niklaus, G., and Burglin, T. 1999. Caenorhabditis elegans has scores of hedgehog-related genes: Sequence and expression analysis. Genome Res. 9: 909-23.

Aza-Blanc, P., Ramirezweber, F., Laget, M., Schwartz, C., and Kornberg, T. 1997. Proteolysis that is inhibited by hedgehog targets cubitus interruptus protein to the nucleus and converts it to a repressor. Cell 89: 1043-1053.

Aza-Blanc, P., Lin, H., Ruiz i Altaba, A., and Kornberg, T. 2000. Expression of the vertebrate Gli proteins in Drosophila reveals a distribution of activator and repressor activities. Development 127: 4293-4301.

Basler, K. and Struhl, G. 1994. Compartment boundaries and the control of Drosophila limb pattern by Hedgehog protein. $\mathrm{Na}$ ture 368: 208-214.

Bellaiche, Y., The, I., and Perrimon, N. 1998. tout-velu is a 
Drosophila homologue of the putative tumour suppressor EXT-1 and is needed for Hh diffusion. Nature 394: 85-88.

Belloni, E., Muenke, M., Roessler, E., Traverso, G., Siegel-Bartelt, J., Frumkin, A., Mitchell, H., Donis-Keller, H., Helms, C., Hing, A., et al. 1996. Identification of Sonic hedgehog as a candidate gene responsible for holoprosencephaly. Nat. Genet. 14: 353-356.

Bellusci, S., Furuta, Y., Rush, M., Henderson, R., Winnier, G., and Hogan, B. 1997. Involvement of Sonic hedgehog (Shh) in mouse embryonic lung growth and morphogenesis. Development 124: 53-63.

Betsholtz, C., Karlsson, L., and Lindahl, P. 2001. Developmental roles of platelet-derived growth factors. BioEssays 23: 494 507.

Bhardwaj, G., Murdoch, B., Wu, D., Baker, D., Williams, K., Chadwick, K., Ling, L., Karanu, F., and Bhatia, M. 2001. Sonic hedgehog induces the proliferation of primitive human hematopoietic cells via BMP regulation. Nat. Immunol. 2: 172-180.

Bingham, S., Nasevicius, A., Ekker, S., and Chandrasekhar, A. 2001. Sonic hedgehog and Tiggy-winkle hedgehog cooperatively induce zebrafish branchiomotor neurons. Genesis 30: $170-174$.

Bitgood, M., Shen, L., and McMahon, A. 1996. Sertoli-cell signaling by Desert hedgehog regulates the male germline. Curr. Biol. 6: 298-304.

Blagden, C., Currie, P., Ingham, P., and Hughes, S. 1997. Notochord induction of zebrafish slow muscle is mediated by Sonic hedgehog. Genes \& Dev. 11: 2163-2175.

Blanchette-Mackie, E. 2000. Intracellular cholesterol trafficking: Role of the NPC1 protein. Biochim. Biophys. Acta 1486: $171-183$.

Borycki, A. 2001. Sonic hedgehog and Wnt signalling pathways during development and evolution. In Modularity in development and evolution (ed. G. Schlosser), Chicago University Press, Chicago (in press).

Borycki, A., Brunk, B., Tajbakhsh, S., Buckingham, M., Chiang, C., and Emerson, C. 1999. Sonic hedgehog controls epaxial muscle determination through myf5 activation. Development 126: 4053-4063.

Briscoe, J., Pierani, A., Jessell, T., and Ericson, J. 2000. A homeodomain protein code specifies progenitor cell identity and neuronal fate in the ventral neural tube. Cell 101: 435445.

Briscoe, J., Chen, Y., Jessell, T., and Struhl, G. 2001. A Hedgehog-insensitive form of Patched provides evidence for direct long-range morphogen activity of Sonic hedgehog in the neural tube. Mol. Cell 7: 1279-1291.

Britto, J. and Tannahill, D. 2000. Life, death and Sonic hedgehog. BioEssays 22: 499-502.

Bruckner, K. and Klein, R. 1998. Signaling by Eph receptors and their ephrin ligands. Curr. Opin. Neurobiol. 8: 375-382.

Bumcrot, D.A., Takada, R., and McMahon, A.P. 1995. Proteolytic processing yields two secreted forms of Sonic hedgehog. Mol. Cell. Biol. 15: 2294-2303.

Burke, R., Nellen, D., Bellotto, M., Hafen, E., Senti, K.A., Dickson, B.J., and Basler, K. 1999. Dispatched, a novel sterolsensing domain protein dedicated to the release of cholesterol-modified Hedgehog from signaling cells. Cell 99: 803815.

Buscher, D., Bosse, B., Heymer, J., and Ruther, U. 1997. Evidence for genetic control of Sonic hedgehog by Gli3 in mouse limb development. Mech. Dev. 62: 175-182.

Capdevila, J. and Guerrero, I. 1994. Targetted expression of the signalling molecule decapentaplegic induces pattern duplications and growth alterations in Drosophila wings. EMBO
J. 13: 4459-4468.

Capdevila, J., Estrada, M.P., Sanchez-Herrero, E., and Guerrero, I. 1994a. The Drosophila segment polarity gene patched interacts with decapentaplegic in wing development. EMBO I. 13: $71-82$.

Capdevila, J., Pariente, F., Sampedro, J., Alonso, J.L., and Guerrero, I. 1994b. Subcellular localisation of the segment polarity protein patched suggests an interaction with the wingless reception complex in Drosophila embryos. Development 120: $987-998$.

Carpenter, D., Stone, D.M., Brush, J., Ryan, A., Armanini, M., Frantz, G., Rosenthal, A., and de Sauvage, F.J. 1998. Characterization of two patched receptors for the vertebrate hedgehog protein family. Proc. Natl. Acad. Sci. 95: 13630-13634.

Carstea, E., Morris, J., Coleman, K., Loftus, S., Zhang, D., Cummings, C., Gu, J., Rosenfeld, M., Pavan, W., Krizman, D., et al. 1997. Niemann-Pick Cl disease gene: Homology to mediators of cholesterol homeostasis. Science 277: 228-231.

Chamoun, Z., Mann, R., Nellen, D., von Kessler, D., Bellotto, M., Beachy, P., and Basler, K. 2001. Skinny hedgehog, an acyltransferase required for palmitoylation and activity of the secreted Hedgehog protein signal. Science 293: 2080-2084.

Chang, D., Lopez, A., von Kessler, D., Chiang, C., Simandl, B., Zhao, R., Seldin, M., Fallon, J., and Beachy, P. 1994. Products, genetic linkage and limb patterning activity of a murine hedgehog gene. Development 120: 3339-3353.

Chen, W., Burgess, S., and Hopkins, N. 2001. Analysis of the zebrafish smoothened mutant reveals conserved and divergent functions of hedgehog activity. Development 128: $2385-2396$.

Chen, Y. and Struhl, G. 1996. Dual roles for patched in sequestering and transducing Hedgehog. Cell 87: 553-563.

Chen, Y., Gallaher, N., Goodman, R., and Smolik, S. 1998. Protein kinase A directly regulates the activity and proteolysis of Cubitus interruptus. Proc. Nat. Acad Sci. 95: 2349-2354.

Chen, Y., Cardinaux, J., Goodman, R., and Smolik, S. 1999. Mutants of cubitus interruptus that are independent of PKA regulation are independent of hedgehog signaling. Development 126: 3607-3616.

Chiang, C., Litingtung, Y., Lee, E., Young, K.E., Corden, J.L., Westphal, H., and Beachy, P.A. 1996. Cyclopia and defective axial patterning in mice lacking Sonic hedgehog gene function. Nature 383: 407-413.

Chiang, C., Swan, R., Grachtchouk, M., Bolinger, M., Litingtung, Y., Robertson, E., Cooper, M., Gaffield, W., Westphal, H., Beachy, P., et al. 1999. Essential role for Sonic hedgehog during hair follicle morphogenesis. Dev. Biol. 205: 1-9.

Chiang, C., Litingtung, Y., Harris, M., Simandl, B., Li, Y., Beachy, P., and Fallon, J. 2001. Manifestation of the limb prepattern: Limb development in the absence of Sonic hedgehog function. Dev. Biol. 236: 421-435.

Chuang, P. and McMahon, A. 1999. Vertebrate Hedgehog signalling modulated by induction of a Hedgehog-binding protein. Nature 397: 617-621.

Chung, U., Schipani, E., McMahon, A., and Kronenberg, H. 2001. Indian hedgehog couples chondrogenesis to osteogenesis in endochondral bone development. J. Clin. Invest. 107: 295-304.

Clark, A., Garland, K., and Russell, L. 2000. Desert hedgehog (Dhh) gene is required in the mouse testis for formation of adult-type Leydig cells and normal development of peritubular cells and seminiferous tubules. Biol. Reprod. 63: 18251838.

Coutelle, O., Blagden, C., Hampson, R., Halai, C., Rigby, P., and Hughes, S. 2001. Hedgehog signalling is required for main- 
tenance of myf5 and myoD expression and timely terminal differentiation in zebrafish adaxial myogenesis. Dev. Biol. 236: 136-150.

Crozatier, M., Valle, D., Dubois, L., Ibnsouda, S., and Vincent, A. 1996. Collier, a novel regulator of Drosophila head development, is expressed in a single mitotic domain. Curr. Biol. 6: 707-718.

Currie, P.D. and Ingham, P.W. 1996. Induction of a specific muscle cell type by a novel hedgehog gene family member. Nature 382: 452-455.

Dahmane, N. and Ruiz-i-Altaba, A. 1999. Sonic hedgehog regulates the growth and patterning of the cerebellum. Development 126: 3089-3100.

Dahmane, N., Lee, J., Robins, P., Heller, P., and Ruiz i Altaba, A. 1997. Activation of the transcription factor Glil and Sonic hedgehog signalling pathways in skin tumours. Nature 389: 876-881.

Dai, P., Akimaru, H., Tanaka, Y., Maekawa, T., Nakafuku, M., and Ishii, S. 1999. Sonic hedgehog-induced activation of the Glil promoter is mediated by GLI3. J. Biol. Chem. 274: 8143-8152.

Dale, J., Vesque, C., Lints, T., Sampath, T., Furley, A., Dodd, J., and Placzek, M. 1997. Cooperation of BMP7 and SHH in the induction of forebrain ventral midline cells by prechordal mesoderm. Cell 90: 257-269.

Dann, C., Hsieh, J., Rattner, A., Sharma, D., Nathans, J., and Leahy, D. 2001. Insights into Wnt binding and signalling from the structures of two Frizzled cysteine-rich domains. Nature 412: 86-90.

Dassule, H. and McMahon, A. 1998. Analysis of epithelial-mesenchymal interactions in the initial morphogenesis of the mammalian tooth. Dev. Biol. 202: 215-227.

Dassule, H., Lewis, P., Bei, M., Maas, R., and McMahon, A. 2000. Sonic hedgehog regulates growth and morphogenesis of the tooth. Development 127: 4775-4785.

Davies, J., Chen, F., and Ioannou, Y. 2000. Transmembrane molecular pump activity of Niemann-Pick C1 protein. Science 290: $2295-2298$

DeBose-Boyd, R.A., Brown, M.S., Li, W.P., Nohturfft, A., Goldstein, J.L., and Espenshade, P.J. 1999. Transport-dependent proteolysis of SREBP: Relocation of site-1 protease from Golgi to ER obviates the need for SREBP transport to Golgi. Cell 99: 703-712.

DeCamp, D., Thompson, T., de Sauvage, F., and Lerner, M. 2000. Smoothened activates $\mathrm{G} \alpha_{\mathrm{i}}$-mediated signaling in frog melanophores. J. Biol. Chem. 275: 26322-26327.

Denef, N., Neubuser, D., Perez, L., and Cohen, S. 2000. Hedgehog induces opposite changes in turnover and subcellular localization of patched and smoothened. Cell 102: 521-531.

Deshpande, G., Swanhart, L., Chiang, P., and Schedl, P. 2001. Hedgehog signaling in germ cell migration. Cell 106: 759769 .

Diaz-Benjumea, F.J., Cohen, B., and Cohen, S.M. 1994. Cell interaction between compartments establishes the proximaldistal axis of Drosophila legs. Nature 372: 175-179.

DiNardo, S., Sher, E., Heemskerk-Jongens, J., Kassis, J., and O'Farrell, P. 1988. Two tiered regulation of spatially patterned engrailed gene expression during Drosophila embryogenesis. Nature 332: 604-609.

Ding, Q., Motoyama, J., Gasca, S., Mo, R., Sasaki, H., Rossant, J., and Hui, C. 1998. Diminished Sonic hedgehog signaling and lack of floor plate differentiation in Gli2 mutant mice. Development 125: 2533-2543.

Ding, Q., Fukami, S., Meng, X., Nishizaki, Y., Zhang, X., Sasaki, H., Dlugosz, A., Nakafuku, M., and Hui, C. 1999. Mouse suppressor of fused is a negative regulator of Sonic hedgehog signaling and alters the subcellular distribution of Gli1. Curr. Biol. 9: 1119-1122.

Dominguez, M. 1999. Dual role for Hedgehog in the regulation of the proneural gene atonal during ommatidia development. Development 126: 2345-2353.

Dominguez, M., Brunner, M., Hafen, E., and Basler, K. 1996. Sending and receiving the Hedgehog signal-Control by the Drosophila Gli protein Cubitus interruptus. Science 272: 1621-1625.

Drossopoulou, G., Lewis, K., Sanz-Ezquerro, J., Nikbakht, N. McMahon, A., Hofmann, C., and Tickle, C. 2000. A model for anteroposterior patterning of the vertebrate limb based on sequential long- and short-range Shh signalling and Bmp signalling. Development 127: 1337-1348.

Duprez, D., Coltey, M., Amthor, H., Brickell, P., and Tickle, C. 1996. Bone morphogenetic protein-2 (BMP-2) inhibits muscle development and promotes cartilage formation in chick limb bud cultures. Dev. Biol. 174: 448-452.

Duprez, D., Fournier-Thibault, C., and Le Douarin, N. 1998. Sonic hedgehog induces proliferation of committed skeletal muscle cells in the chick limb. Development 125: 495-505.

Duprez, D., Lapointe, F., Edom-Vovard, F., Kostakopoulou, K., and Robson, L. 1999. Sonic hedgehog (SHH) specifies muscle pattern at tissue and cellular chick level, in the chick limb bud. Mech. Dev. 82: 151-163.

Dyer, M., Farrington, S., Mohn, D., Munday, J., and Baron, M. 2001. Indian hedgehog activates hematopoiesis and vasculogenesis and can respecify prospective neurectodermal cell fate in the mouse embryo. Development 128: 1717-1730.

Echelard, Y., Epstein, D.J., St-Jacques, B., Shen, L., Mohler, J., McMahon, J.A., and McMahon, A.P. 1993. Sonic hedgehog, a member of a family of putative signaling molecules, is implicated in the regulation of CNS polarity. Cell 75: 14171430.

Eggenschwiler, J. and Anderson, K. 2000. Dorsal and lateral fates in the mouse neural tube require the cell-autonomous activity of the open brain gene. Dev. Biol. 227: 648-660.

Eggenschwiler, J., Espinoza, E., and Anderson, K. 2001. Rab23 is an essential negative regulator of the mouse Sonic hedgehog signalling pathway. Nature 412: 194-198.

Ekker, S., McGrew, L., Lai, C., Lee, J., von Kessler, D., Moon, R., and Beachy, P. 1995a. Distinct expression and shared activities of members of the hedgehog gene family of Xenopus laevis. Development 121: 2337-2347.

Ekker, S., Ungar, A., Greenstein, P., von Kessler, D., Porter, J., Moon, R., and Beachy, P. 1995b. Patterning activities of vertebrate hedgehog proteins in the developing eye and brain. Curr. Biol. 5: 944-955.

Enomoto-Iwamoto, M. and Nakamura, T. 2000. Hedgehog proteins stimulate chondrogenic cell differentiation and cartilage formation. J. Bone Miner. Res. 15: 1659-1668.

Ericson, J., Muhr, J., Placzek, M., Lints, T., Jessell, T., and Edlund, T. 1995. Sonic hedgehog induces the differentiation of ventral forebrain neurons: A common signal for ventral patterning within the neural tube. Cell 81: 747-756.

Fan, C.-M. and Tessier-Lavigne, M. 1994. Patterning of mammalian somites by the surface ectoderm and the notochord: Evidence for scleretome induction by Sonic hedgehog/Vhh1. Cell 79: 1175-1186.

Fernandez-Teran, M., Piedra, M., Kathiriya, I., Srivastava, D., Rodriguez-Rey, J., and Ros, M. 2000. Role of dHAND in the anterior-posterior polarization of the limb bud: Implications for the Sonic hedgehog pathway. Development 127: 2133 2142 .

Fietz, M., Jacinto, A., Taylor, A., Alexandre, C., and Ingham, P. 1995. Secretion of the amino-terminal fragment of the 
Hedgehog protein is necessary and sufficient for hedgehog activity in Drosophila. Curr. Biol. 6: 643-650.

Fjose, A., McGinnis, W., and Gehring, W. 1985. Isolation of a homeobox containing gene from the engrailed region of Drosophila and the spatial distribution of its transcripts. Nature 313: 284-289.

Forbes, A., Nakano, Y., Taylor, A., and Ingham, P. 1993. Genetic analysis of hedgehog signalling in the Drosophila embryo. Development Suppl.: 115-124.

Forbes, A.J., Lin, H., Ingham, P.W., and Spradling, A.C. 1996. hedgehog is required for the proliferation and specification of somatic cells during egg chamber assembly in Drosophila oogenesis. Development 122: 1125-1135.

Fuse, N., Maiti, T., Wang, B., Porter, J., Hall, T., Leahy, D., and Beachy, P. 1999. Sonic hedgehog protein signals not as a hydrolytic enzyme but as an apparent ligand for patched. Proc. Natl. Acad. Sci. 96: 10992-10999.

Gailani, M., Stahlebackdahl, M., Leffell, D., Glynn, M., Zaphiropoulos, P., Pressman, C., Unden, A., Dean, M., Brash, D., Bale, A., et al. 1996. The role of the human homolog of Drosophila patched in sporadic basal-cell carcinomas. Nat. Genet. 14: 78-81.

Gallet, A., Angelats, C., Kerridge, S., and Therond, P. 2000. Cubitus interruptus-independent transduction of the Hedgehog signal in Drosophila. Development 127: 5509-5522.

Garg, V., Yamagishi, C., Hu, T., Kathiriya, I., Yamagishi, H., and Srivastava, D. 2001. Tbx1, a DiGeorge syndrome candidate gene, is regulated by Sonic hedgehog during pharyngeal arch development. Dev. Biol. 235: 62-73.

Glazer, L. and Shilo, B. 2001. Hedgehog signaling patterns the tracheal branches. Development 128: 1599-1606.

Goodrich, L.V., Johnson, R.L., Milenkovic, L., McMahon, J.A., and Scott, M.P. 1996. Conservation of the hedgehog/patched signaling pathway from flies to mice: Induction of a mouse patched gene by hedgehog. Genes \& Dev. 10: 301-312.

Goodrich, L., Milenkovic, L., Higgins, K., and Scott, M. 1997. Altered neural cell fates and medulloblastoma in mouse patched mutants. Science 277: 1109-1113.

Grindley, J. and Bellusci, S. 1997. Evidence for the involvement of the Gli gene family in embryonic mouse lung development. Dev. Biol. 188: 337-348.

Gritli-Linde, A., Lewis, P., McMahon, A., and Linde, A. 2001. The whereabouts of a morphogen: Direct evidence for shortand graded long-range activity of hedgehog signaling peptides. Dev. Biol. 236: 364-386.

Gunhaga, L., Jessell, T., and Edlund, T. 2000. Sonic hedgehog signaling at gastrula stages specifies ventral telencephalic cells in the chick embryo. Development 127: 3283-3293.

Gunther, T., Struwe, M., Aguzzi, A., and Schughart, K. 1994. Open brain, a new mouse mutant with severe neural tube defects, shows altered gene expression patterns in the developing spinal cord. Development 120: 3119-3130.

Hall, T.M.T., Porter, J.A., Beachy, P.A., and Leahy, D.J. 1995. A potential catalytic site revealed by the $1.7-\AA$ crystal structure of the amino-terminal signalling domain of Sonic hedgehog. Nature 378: 212-216.

Hammerschmidt, M. and McMahon, A. 1998. The effect of pertussis toxin on zebrafish development: A possible role for inhibitory G-proteins in hedgehog signaling. Dev. Biology 194: $166-171$.

Hardcastle, Z., Mo, R., Hui, C., and Sharpe, P. 1998. The Shh signalling pathway in tooth development: Defects in Gli2 and Gli3 mutants. Development 125: 2803-2811.

Heberlein, U., Singh, C., Luk, A., and Donohoe, T. 1995. Growth and differentiation in the Drosophila eye coordinated by hedgehog. Nature 373: 709-711.
Hebrok, M., Kim, S., St Jacques, B., McMahon, A., and Melton, D. 2000. Regulation of pancreas development by hedgehog signaling. Development 127: 4905-4913.

Helms, J., Kim, C., Hu, D., Minkoff, R., Thaller, C., and Eichele, G. 1997. Sonic hedgehog participates in craniofacial morphogenesis and is down-regulated by teratogenic doses of retinoic acid. Dev. Biol. 187: 25-35.

Hidalgo, A. 1994. Three distinct roles for the engrailed gene in Drosophila wing development. Curr. Biol. 4: 1087-1098.

Hidalgo, A. and Ingham, P. 1990. Cell patterning in the Drosophila segment: Spatial regulation of the segment polarity gene patched. Development 110: 291-302.

Higgins, M., Davies, J., Chen, F., and Ioannou, Y. 1999. Niemann-Pick $\mathrm{Cl}$ is a late endosome-resident protein that transiently associates with lysosomes and the trans-Golgi network. Mol. Genet. Metab. 68: 1-13.

Hooper, J. 1994. Distinct pathways for autocrine and paracrine Wingless signalling in Drosophila embryos. Nature 372: 461-464.

Hua, X., Nohturfft, A., Goldstein, J., and Brown, M. 1996. Sterol resistance in $\mathrm{CHO}$ cells traced to point mutation in SREBP cleavage-activating protein. Cell 87: 415-426.

Huang, Z. and Kunes, S. 1996. Hedgehog, transmitted along retinal axons, triggers neurogenesis in the developing visual centers of the Drosophila brain. Cell 86: 411-422.

- 1998. Signals transmitted along retinal axons in Drosophila: Hedgehog signal reception and the cell circuitry of lamina cartridge assembly. Development 125: 3753-3764.

Hui, C.C. and Joyner, A.L. 1993. A mouse model of Greig cephalopolysyndactyly syndrome: The extra-toesJ mutation contains an intragenic deletion of the Gli3 gene. Nat. Genet. 3: 241-246.

Hynes, M., Porter, J., Chiang, C., Chang, D., Tessier-Lavigne, M., Beachy, P., and Rosenthal, A. 1995. Induction of midbrain dopaminergic neurons by Sonic hedgehog. Neuron 15: $35-44$.

Hynes, M., Stone, D., Dowd, M., Pitts-Meek, S., Goddard, A., Gurney, A., and Rosenthal, A. 1997. Control of cell pattern in the neural tube by the zinc finger transcription factor and oncogene Gli-1. Neuron 19: 15-26.

Hynes, M., Ye, W., Wang, K., Stone, D., Murone, M., Sauvage, F., and Rosenthal, A. 2000. The seven-transmembrane receptor smoothened cell-autonomously induces multiple ventral cell types. Nat. Neurosci. 3: 41-46.

Incardona, J., Gaffield, W., Lange, Y., Cooney, A., Pentchev, P., Liu, S., Watson, J., Kapur, R., and Roelink, H. 2000a. Cyclopamine inhibition of Sonic hedgehog signal transduction is not mediated through effects on cholesterol transport. Dev. Biol 224: 440-452.

Incardona, J., Lee, J., Robertson, C., Enga, K., Kapur, R., and Roelink, H. 2000b. Receptor-mediated endocytosis of soluble and membrane-tethered Sonic hedgehog by patched1. Proc. Nat1. Acad. Sci. 97: 12044-12049.

Ingham, P.W. 1991. Segment polarity genes and cell patterning within the Drosophila body segment. Curr. Opin. Genet. Dev. 1: 261-267.

Ingham, P.W. 1998. The patched gene in development and cancer. Curr. Opin. Genet. Dev. 8: 88-95.

Ingham, P.W. and Fietz, M.J. 1995. Quantitative effects of hedgehog and decapentaplegic activity on the patterning of the Drosophila wing. Curr. Biol. 5: 432-441.

Ingham, P.W. and Hidalgo, A. 1993. Regulation of wingless transcription in the Drosophila embryo. Development 117: 283291.

Ingham, P.W., Taylor, A.M., and Nakano, Y. 1991. Role of the Drosophila patched gene in positional signalling. Nature 
353: $184-187$.

Ingham, P., Nystedt, S., Nakano, Y., Brown, W., Stark, D., van den Heuvel, M., and Taylor, A. 2000. Patched represses the Hedgehog signalling pathway by promoting modification of the Smoothened protein. Curr. Biol 10: 1315-1318.

Jensen, A.M. and Wallace, V.A. 1997. Expression of Sonic hedgehog and its putative role as a precursor cell mitogen in the developing mouse retina. Development 124: 363-371.

Jessell, T. 2000. Neuronal specification in the spinal cord: Inductive signals and transcriptional codes. Nat. Rev. Genet. 1: 20-29.

Jiang, J. and Struhl, G. 1995. Protein kinase A and hedgehog signaling in Drosophila limb development. Cell 80: $563-572$.

Johnson, R.L., Laufer, E., Riddle, R.D., and Tabin, C. 1994. Ectopic expression of Sonic hedgehog alters dorsal-ventral patterning of somites. Cell 79: 1165-1173.

Johnson, R.L., Grenier, J.K., and Scott, M.P. 1995. patched overexpression alters wing disc size and pattern: Transcriptional and post-transcriptional effects on hedgehog targets. Development 121: 4161-4170.

Johnson, R., Milenkovic, L., and Scott, M. 2000. In vivo functions of the Patched protein: Requirement of the $\mathrm{C}$ terminus for target gene inactivation but not Hedgehog sequestration. Mol. Cell 6: 467-478.

Karlsson, L., Bondjers, C., and Betsholtz, C. 1999. Roles for PDGF-A and sonic hedgehog in development of mesenchymal components of the hair follicle. Development 126: 2611-2621.

Karlstrom, R.O., Talbot, W.S., and Schier, A.F. 1999. Comparative synteny cloning of zebrafish you-too: Mutations in the Hedgehog target gli2 affect ventral forebrain patterning. Genes \& Dev. 13: 388-393.

Karp, S.J., Schipani, E., St-Jacques, B., Hunzelman, J., Kronenberg, H., and McMahon, A.P. 2000. Indian hedgehog coordinates endochondral bone growth and morphogenesis via parathyroid hormone related-protein-dependent and -independent pathways. Development 127: 543-548.

Karpen, H.E., Bukowski, J.T., Hughes, T., Gratton, J.P., Sessa, W.C., and Gailani, M.R. 2001. The sonic hedgehog receptor patched associates with caveolin-1 in cholesterol-rich microdomains of the plasma membrane. I. Biol. Chem. 276: 19503-19511.

Kenney, A. and Rowitch, D. 2000. Sonic hedgehog promotes G(1) cyclin expression and sustained cell cycle progression in mammalian neuronal precursors. Mol. Cell. Biol. 20: 90559067.

Kim, S. and Melton, D. 1998. Pancreas development is promoted by cyclopamine, a hedgehog signaling inhibitor. Proc. Natl. Acad. Sci. 95: 13036-13041.

Ko, D., Gordon, M., Jin, J., and Scott, M. 2001. Dynamic movements of organelles containing Niemann-Pick C1 protein: NPC1 involvement in late endocytic events. Mol. Biol. Cell 12: 601-614.

Kobayashi, T., Beuchat, M., Lindsay, M., Frias, S., Palmiter, R., Sakuraba, H., Parton, R., and Gruenberg, J. 1999. Late endosomal membranes rich in lysobisphosphatidic acid regulate cholesterol transport. Nat. Cell Biol. 1: 113-118.

Kogerman, P., Grimm, T., Kogerman, L., Krause, D., Unden, A.B., Sandstedt, B., Toftgard, R., and Zaphiropoulos, P.G. 1999. Mammalian suppressor-of-fused modulates nuclearcytoplasmic shuttling of Gli-1. Nat. Cell Biol. 1: 312-319.

Kohtz, J., Baker, D., Corte, G., and Fishell, G. 1998. Regionalization within the mammalian telencephalon is mediated by changes in responsiveness to Sonic hedgehog. Development 125: 5079-5089.
Kohtz, J., Lee, H., Gaiano, N., Segal, J., Ng, E., Larson, T., Baker, D., Garber, E., Williams, K., and Fishell, G. 2001. N-terminal fatty-acylation of sonic hedgehog enhances the induction of rodent ventral forebrain neurons. Development 128: 23512363.

Kondoh, H., Uchikawa, M., Yoda, H., Takeda, H., FurutaniSeiki, M., and Karlstrom, R. 2000. Zebrafish mutations in Gli-mediated hedgehog signaling lead to lens transdifferentiation from the adenohypophysis anlage. Mech. Dev. 96: $165-174$.

Kraus, P., Fraidenraich, D., and Loomis, C. 2001. Some distal limb structures develop in mice lacking Sonic hedgehog signaling. Mech. Dev. 100: 45-58.

Krauss, S., Concordet, J.-P., and Ingham, P.W. 1993. A functionally conserved homolog of the Drosophila segment polarity gene hedgehog is expressed in tissues with polarising activity in zebrafish embryos. Cell 75: 1431-1444.

Krishnan, V., Pereira, F., Qiu, Y., Chen, C., Beachy, P., Tsai, S., and Tsai, M. 1997. Mediation of Sonic hedgehog induced expression of COUP-TFII by a protein phosphatase. Science 278: 1947-1950.

Kruger, M., Mennerich, D., Fees, S., Schafer, R., Mundlos, S., and Braun, T. 2001. Sonic hedgehog is a survival factor for hypaxial muscles during mouse development. Development 128: $743-752$.

Kuwabara, P.E., Lee, M.-H., Schedl, T., and Jefferis, G.S.X.E. 2000. A C. elegans patched gene, ptc-1, functions in germline cytokinesis. Genes \& Dev. 14: 1933-1944.

Lai, C., Ekker, S., Beachy, P., and Moon, R. 1995. Patterning of the neural ectoderm of Xenopus laevis by the amino-terminal product of hedgehog autoproteolytic cleavage. Development 121: 2349-2360.

LaMantia, A., Bhasin, N., Rhodes, K., and Heemskerk, J. 2000. Mesenchymal/epithelial induction mediates olfactory pathway formation. Neuron 28: 411-425.

Lanske, B., Karaplis, A.C., Lee, K., Luz, A., Vortkamp, A., Pirro, A., Karperien, M., Defize, L.H., Ho, C., Mulligan, R.C., et al. 1996. PTH/PTHrP receptor in early development and Indian hedgehog-regulated bone growth. Science 273: 663-666.

Laufer, E., Nelson, C., Johnson, R., Morgan, B., and Tabin, C. 1994. Sonic hedgehog and Fgf-4 Act through a signalling cascade and feedback loop to integrate growth and patterning of the developing limb bud. Cell 79: 993-1003.

Lee, J. and Treisman, J. 2001. Sightless has homology to transmembrane acyltransferases and is required to generate active Hedgehog protein. Curr. Biol. 11: 1147-1152.

Lee, J.J., von Kessler, D.P., Parks, S., and Beachy, P.A. 1992. Secretion and localised transcription suggests a role in positional signalling for products of the segmentation gene hedgehog. Cell 70: 777-789.

Lee, J.J., Ekker, S.C., von Kessler, D.P., Porter, J.A., Sun, B.I., and Beachy, P.A. 1994. Autoproteolysis in hedgehog protein biogenesis. Science 266: 1528-1537.

Lee, J., Platt, K., Censullo, P., and Altaba, A. 1997. Glil is a target of sonic hedgehog that induces ventral neural-tube development. Development 124: 2537-2552.

Lee, J., Kraus, P., Gaiano, N., Nery, S., Kohtz, J., Fishell, G., Loomis, C., and Treisman, J. 2001. An acylatable residue of Hedgehog is differentially required in Drosophila and mouse limb development. Dev. Biol. 233: 122-136.

Lee, K. and Jessell, T. 1999. The specification of dorsal cell fates in the vertebrate central nervous system. Annu. Rev. Neurosci. 22: 261-294.

Levin, M., Johnson, R.L., Stern, C.D., Kuehn, M., and Tabin, C. 1995. A molecular pathway determining left-right asymmetry in chick embryogenesis. Cell 82: 803-814. 
Levine, E., Roelink, H., Turner, J., and Reh, T. 1997. Sonic hedgehog promotes rod photoreceptor differentiation in mammalian retinal cells in vitro. J. Neurosci. 17: 6277-6288.

Lewis, K.E., Concordet, J.-P., and Ingham, P.W. 1999a. Characterisation of a second patched gene in the zebrafish Danio rerio and the differential response of patched genes to Hedgehog signalling. Dev. Biol. 208: 14-29.

Lewis, K.E., Currie, P.D., Roy, S., Schuarte, H., Haffter, P., and Ingham, P.W. 1999b. Control of muscle cell-type specification in the zebrafish embryo by Hedgehog signalling. Dev. Biol. 216: 469-480.

Lewis, P., Dunn, M., McMahon, J., Logan, M., Martin, J., StJacques, B., and McMahon, A. 2001. Cholesterol modification of sonic hedgehog is required for long-range signaling activity and effective modulation of signaling by Ptc1. Cell 105: 599-612.

Lind, T., Tufaro, F., McCormick, C., Lindahl, U., and Lidholt, K. 1998. The putative tumor suppressors EXT1 and EXT2 are glycosyltransferases required for the biosynthesis of heparan sulfate. J. Biol. Chem. 273: 26265-26268.

Litingtung, Y. and Chiang, C. 2000. Specification of ventral neuron types is mediated by an antagonistic interaction between Shh and Gli3. Nat. Neurosci. 3: 979-985.

Litingtung, Y., Lei, L., Westphal, H., and Chiang, C. 1998. Sonic hedgehog is essential to foregut development. Nat. Genet. 20: $58-61$.

Loftus, S., Morris, J., Carstea, E., Gu, J., Cummings, C., Brown, A., Elison, J., Ohno, K., Rosenfeld, M.A., et al. 1997. Murine model of Niemann-Pick C diseases: Mutation in a cholesterol homeostasis gene. Science 277: 232-234.

Lu, Q.R., Yuk, D., Alberta, J.A., Zhu, Z., Pawlitzky, I., Chan, J., McMahon, A.P., Stiles, C.D., and Rowitch, D.H. 2000. Sonic hedgehog-regulated oligodendrocyte lineage genes encoding bHLH proteins in the mammalian central nervous system. Neuron 25: 317-329.

Macdonald, R., Barth, K.A., Xu, Q., Holder, N., Mikkola, I., and Wilson, S.W. 1995. Midline signalling is required for Pax gene regulation and patterning of the eyes. Development 121: 3267-3278.

Marigo, V. and Tabin, C. 1996. Regulation of patched by sonic hedgehog in the developing neural tube. Proc. Natl. Acad. Sci. 93: 9346-9351.

Marigo, V., Davey, R., Zuo, Y., Cunningham, J., and Tabin, C. 1996a. Biochemical evidence that patched is the hedgehog receptor. Nature 384: 176-179.

Marigo, V., Johnson, R., Vortkamp, A., and Tabin, C. 1996b. Sonic hedgehog differentially regulates expression of Gli and Gli3 during limb development. Dev. Biol. 180: 273-283.

Marigo, V., Scott, M.P., Johnson, R.L., Goodrich, L.V., and Tabin, C.J. 1996c. Conservation in hedgehog signaling: Induction of a chicken patched homolog by Sonic hedgehog in the developing limb. Development 122: 1225-1233.

Marti, E., Bumcrot, D.A., Takada, R., and McMahon, A.P. 1995. Requirement of 19K form of Sonic hedgehog for induction of distinct ventral cell types in CNS explants. Nature 375: 322 325.

Martin, V., Carrillo, G., Torroja, C., and Guerrero, I. 2001. The sterol-sensing domain of Patched protein seems to control Smoothened activity through Patched vesicular trafficking. Curr. Biol. 11: 601-607.

Martinez Arias, A., Baker, N.E., and Ingham, P.W. 1988. Role of segment polarity gene in the definition and maintenance of cell states in the Drosophila embryo. Development 103: $157-170$.

Massague, J. and Chen, Y. 2000. Controlling TGF- $\beta$ signaling. Genes \& Dev. 14: 627-644.
Mastronardi, F., Dimitroulakos, J., Kamel-Reid, S., and Manoukian, A. 2000. Co-localization of patched and activated sonic hedgehog to lysosomes in neurons. Neuroreport 11: $581-585$.

Masuya, H., Sagai, T., Wakana, S., Moriwaki, K., and Shiroishi, T. 1995. A duplicated zone of polarizing activity in polydactylous mouse mutants. Genes \& Dev. 9: 1645-1653.

Matise, M., Epstein, D., Park, H., Platt, K., and Joyner, A. 1998. Gli2 is required for induction of floor plate and adjacent cells, but not most ventral neurons in the mouse central nervous system. Development 125: 2759-2770.

McMahon, A.P., Joyner, A.L., Bradley, A., and McMahon, J.A. 1992. The midbrain-hindbrain phenotype of Wnt-1 ${ }^{-} / \mathrm{Wnt}-1^{-}$ mice results from stepwise deletion of engrailed-expressing cells by 9.5 days postcoitum. Cell 69: $581-595$.

Methot, N. and Basler, K. 1999. Hedgehog controls limb development by regulating the activities of distinct transcriptional activator and repressor forms of Cubitus interruptus. Cell 96: 819-831.

- 2000. Suppressor of fused opposes hedgehog signal transduction by impeding nuclear accumulation of the activator form of Cubitus interruptus. Development 127: 4001-4010. . 2001. An absolute requirement for Cubitus interruptus in Hedgehog signaling. Development 128: 733-742.

Meyers, E. and Martin, G. 1999. Differences in left-right axis pathways in mouse and chick: Functions of FGF8 and SHH. Science 285: 403-406.

Michaux, G., Gansmuller, A., Hindelang, C., and Labouesse, M. 2000. CHE-14, a protein with a sterol-sensing domain, is required for apical sorting in C. elegans ectodermal epithelial cells. Curr. Biol. 10: 1098-1107.

Miura, H., Kusakabe, Y., Sugiyama, C., Kawamatsu, M., Ninomiya, Y., Motoyama, J., and Hino, A. 2001. Shh and Ptc are associated with taste bud maintenance in the adult mouse. Mech. Dev. 106: 143-145.

Mo, R., Freer, A., Zinyk, D., Crackower, M., Michaud, J., Heng, H., Chik, K., Shi, X., Tsui, L., Cheng, S., et al. 1997. Specific and redundant functions of Gli2 and Gli3 zinc finger genes in skeletal patterning and development. Development 124: $113-123$

Mohler, J. 1988. Requirements for hedgehog, a segment polarity gene, in patterning larval and adult cuticle of Drosophila. Genetics 120: 1061-1072.

Mohler, J. and Vani, K. 1992. Molecular organisation and embryonic expression of the hedgehog gene involved in cellcell communication in segmental patterning in Drosophila. Development 115: 957-971.

Mohler, J., Seecoomar, M., Agarwal, S., Bier, E., and Hsai, J. 2000. Activation of knot $(\mathrm{kn})$ specifies the 3-4 intervein region in the Drosophila wing. Development 127: 55-63.

Monnier, V., Dussillol, F., Alves, G., Lamour-Isnard, C., and Plessis, A. 1998. Molecular interactions between three members of the Drosophila Hedgehog signalling pathway: Suppressor of fused links the ser-thr kinase Fused and the transcription factor Cubitus interruptus. Curr. Biol. 8: 583-586.

Monsoro-Burq, A. and Le Douarin, N. 2001. BMP4 plays a key role in left-right patterning in chick embryos by maintaining Sonic hedgehog asymmetry. Mol. Cell. 7: 789-799.

Morgan, B., Orkin, R., Noramly, S., and Perez, A. 1998. Stagespecific effects of sonic hedgehog expression in the epidermis. Dev. Biol. 201: 1-12.

Motoyama, J. and Liu, J. 1998. Essential function of Gli2 and Gli3 in the formation of lung, trachea and oesophagus. Nat. Genet. 20: 54-57.

Motoyama, J., Takabatake, T., Takeshima, K., and Hui, C. 1998. Ptch2, a second mouse Patched gene is co-expressed with 
Sonic hedgehog. Nat. Genet. 18: 104-106.

Motzny, C.K. and Holmgren, R. 1995. The Drosophila Cubitus interruptus protein and its role in the wingless and hedgehog signal transduction pathways. Mech. Dev 52: 137-150.

Mullor, J. and Guerrero, I. 2000. A gain-of-function mutant of patched dissects different responses to the hedgehog gradient. Dev. Biol. 228: 211-224.

Mullor, J., Calleja, M., Capdevila, J., and Guerrero, I. 1997. Hedgehog activity, independent of decapentaplegic, participates in wing disc patterning. Development 124: 1227-1237.

Munsterberg, A.E., Kitajewski, J., Bumcrot, D.A., McMahon, A.P., and Lassar, A.B. 1995. Combinatorial signaling by Sonic hedgehog and Wnt family members induces myogenic bHLH gene expression in the somite. Genes \& Dev. 9: 29112922.

Murone, M., Rosenthal, A., and de Sauvage, F. 1999. Sonic hedgehog signaling by the patched-smoothened receptor complex. Curr. Biol 9: 76-84.

Murone, M., Luoh, S.M., Stone, D., Li, W., Gurney, A., Armanini, M., Grey, C., Rosenthal, A., and de Sauvage, F.J. 2000. Gli regulation by the opposing activities of fused and suppressor of fused. Nat. Cell Biol. 2: 310-312.

Murtaugh, L., Chyung, J., and Lassar, A. 1999. Sonic hedgehog promotes somitic chondrogenesis by altering the cellular response to BMP signaling. Genes \& Dev. 13: 225-237.

Nakamura, T., Aikawa, T., Iwamoto-Enomoto, M., Iwamoto, M., Higuchi, Y., Pacifici, M., Kinto, N., Yamaguchi, A., Noji, S., Kurisu, K., et al. 1997. Induction of osteogenic differentiation by hedgehog proteins. Biochem. Biophys. Res. Commun. 237: 465-469.

Nellen, D., Burke, R., Struhl, G., and Basler, K. 1996. Direct and long-range action of a dpp morphogen gradient. Cell 85: 357 368.

Nery, S., Wichterle, H., and Fishell, G. 2001. Sonic hedgehog contributes to oligodendrocyte specification in the mammalian forebrain. Development 128: 527-540.

Neufeld, E., Wastney, M., Patel, S., Suresh, S., Cooney, A., Dwyer, N., Roff, C., Ohno, K., Morris, J., Carstea, E., et al. 1999. The Niemann-Pick $\mathrm{C} 1$ protein resides in a vesicular compartment linked to retrograde transport of multiple lysosomal cargo. J. Biol. Chem. 274: 9627-9635.

Neumann, C. and Nüsslein-Volhard, C. 2000. Patterning of the zebrafish retina by a wave of sonic hedgehog activity. Science 289: 2137-2139.

Neumann, C.J., Grandel, H., Gaffield, W., Schulte-Merker, S., and Nüsslein-Volhard, C. 1999. Transient establishment of anteroposterior polarity in the zebrafish pectoral fin bud in the absence of sonic hedgehog activity. Development 126: $4817-4826$.

Niswander, L., Jeffrey, S., Martin, G.R., and Tickle, C. 1994. A positive feedback loop coordinates growth and patterning in the vertebrate limb. Nature 371: 609-612.

Nohturfft, A., DeBose-Boyd, R., Scheek, S., Goldstein, J., and Brown, M. 1999. Sterols regulate cycling of SREBP cleavageactivating protein (SCAP) between endoplasmic reticulum and Golgi. Proc. Nat1. Acad. Sci. 96: 11235-11240.

Norris, W., Neyt, C., Ingham, P., and Currie, P. 2000. Slow muscle induction by Hedgehog signalling in vitro. J. Cell Sci. 113: $2695-2703$.

Nüsslein-Volhard, C. and Wieschaus, E. 1980. Mutations affecting segment number and polarity in Drosophila. Nature 287: 795-801.

Odent, S., Atti-Bitach, T., Blayau, M., Mathieu, M., Aug, J., de Delezo, A., Gall, J., Le Marec, B., Munnich, A., David, V., et al. 1999. Expression of the Sonic hedgehog $(\mathrm{SHH})$ gene during early human development and phenotypic expression of new mutations causing holoprosencephaly. Hum. Mol. Genet. 8: $1683-1689$.

Ohlmeyer, J. and Kalderon, D. 1998. Hedgehog stimulates maturation of Cubitus interruptus into a labile transcriptional activator. Nature 396: 749-753.

Oppenheim, R. and Homma, S. 1999. Modulation of early but not later stages of programmed cell death in embryonic avian spinal cord by sonic hedgehog. Mol. Cell Neurosci. 13: 348361.

Orentas, D., Hayes, J., Dyer, K., and Miller, R. 1999. Sonic hedgehog signaling is required during the appearance of spinal cord oligodendrocyte precursors. Development 126: $2419-2429$.

Outram, S.V., Varas, A., Pepicelli, C.V., and Crompton, T. 2000. Hedgehog signaling regulates differentiation from doublenegative to double-positive thymocyte. Immunity 13: 187197.

Pankratz, M. and Hoch, M. 1995. Control of epithelial morphogenesis by cell signaling and integrin molecules in the Drosophila foregut. Development 121: 1885-1898.

Park, H. and Bai, C. 2000. Mouse Glil mutants are viable but have defects in SHH signaling in combination with a Gli2 mutation. Development 127: 1593-1605.

Parmantier, E., Lynn, B., Lawson, D., Turmaine, M., Namini, S., Chakrabarti, L., McMahon, A., Jessen, K., and Mirsky, R. 1999. Schwann cell-derived Desert hedgehog controls the development of peripheral nerve sheaths. Neuron 23: 713724.

Pathi, S. and Pagan-Westphal, S. 2001. Comparative biological responses to human Sonic, Indian, and Desert hedgehog. Mech. Dev. 106: 107-117.

Pearse II, R.V. , Collier, L.S., Scott, M.P., and Tabin, C.J. 1999. Vertebrate homologs of Drosophila Suppressor of fused interact with the Gli family of transcriptional regulators. Dev. Biol. 212: 323-336.

Pepicelli, C., Lewis, P., and McMahon, A. 1998. Sonic hedgehog regulates branching morphogenesis in the mammalian lung. Curr. Biol. 8: 1083-1086.

Pepinsky, R., Zeng, C., Wen, D., Rayhorn, P., Baker, D., Williams, K., Bixler, S., Ambrose, C., Garber, E., Miatkowski, K., et al. 1998. Identification of a palmitic acid-modified form of human Sonic hedgehog. J. Biol. Chem. 273: 14037-14045.

Placzek, M. 1995. The role of the notochord and floor plate in inductive interactions. Curr. Opin. Genet. Dev. 5: 499-506.

Podlasek, C., Barnett, D., Clemens, J., Bak, P., and Bushman, W. 1999. Prostate development requires Sonic hedgehog expressed by the urogenital sinus epithelium. Dev. Biol. 209: 28-39.

Pola, R., Ling, L., Silver, M., Corbley, M., Kearney, M., Blake Pepinsky, R., Shapiro, R., Taylor, F., Baker, D., Asahara, T., et al. 2001. The morphogen Sonic hedgehog is an indirect angiogenic agent upregulating two families of angiogenic growth factors. Nat. Med. 7: 706-711.

Poncet, C., Soula, C., Trousse, F., Kan, P., Hirsinger, E., Pourquie, O., Duprat, A., and Cochard, P. 1996. Induction of oligodendrocyte progenitors in the trunk neural tube by ventralizing signals: Effects of notochord and floor plate grafts, and of sonic hedgehog. Mech. Dev. 60: 13-32.

Pons, S., Trejo, J., Martinez-Morales, J., and Marti, E. 2001. Vitronectin regulates Sonic hedgehog activity during cerebellum development through CREB phosphorylation. Development 128: 1481-1492.

Poole, S.J., Kauvar, L.M., Drees, B., and Kornberg. 1985. The engrailed locus of Drosophila: Structural analysis of an embryonic transcript. Cell 40: 37-43.

Porter, J.A., von Kessler, D.P., Ekker, S.C., Young, K.E., Lee, J.J., 
Moses, K., and Beachy, P.A. 1995. The product of hedgehog autoproteolytic cleavage active in local and long-range signalling. Nature 374: 363-366.

Porter, J.A., Ekker, S.C., Park, W.J., Vonkessler, D.P., Young, K.E., Chen, C.H., Ma, Y., Woods, A.S., Cotter, R.J., Koonin, E.V., et al. 1996a. Hedgehog patterning activity: Role of a lipophilic modification mediated by the carboxy-terminal autoprocessing domain. Cell 86: 21-34.

Porter, J., Young, K., and Beachy, P. 1996b. Cholesterol modification of hedgehog signaling proteins in animal development. Science 274: 255-259.

Préat, T. 1992. Characterisation of Suppressor of fused, a complete suppressor of the fused segment polarity gene of Drosophila melanogaster. Genetics 132: 725-736.

Price, M. and Kalderon, D. 1999. Proteolysis of cubitus interruptus in Drosophila requires phosphorylation by protein kinase A. Development 126: 4331-4339.

Pringle, N., Yu, W., Guthrie, S., Roelink, H., Lumsden, A., Peterson, A., and Richardson, W. 1996. Determination of neuroepithelial cell fate: Induction of the oligodendrocyte lineage by ventral midline cells and sonic hedgehog. Dev. Biol. 177: 30-42.

Quirk, J., van den Heuvel, M., Henrique, D., Marigo, V., Jones, T., Tabin, C., and Ingham, P. 1997. The smoothened gene and Hedgehog signal transduction in Drosophila and vertebrate development. Cold Spring Harbor Symp. 62: 217-226.

Ramalho-Santos, M., Melton, D., and McMahon, A. 2000. Hedgehog signals regulate multiple aspects of gastrointestinal development. Development 127: 2763-2772.

Ramirez-Weber, F., Casso, D., Aza-Blanc, P., Tabata, T., and Kornberg, T. 2000. Hedgehog signal transduction in the posterior compartment of the Drosophila wing imaginal disc. Mol. Cell 6: 479-485.

Riddle, R., Johnson, R., Laufer, E., and Tabin, C. 1993. Sonic hedgehog mediates the polarizing activity of the ZPA. Cell 75: 1401-1416.

Rietveld, A., Neutz, S., Simons, K., and Eaton, S. 1999. Association of sterol- and glycosylphosphatidylinositol-linked proteins with Drosophila raft lipid microdomains. J. Biol. Chem. 274: 12049-12054.

Rijsewijk, F., Schuermann, M., Wagenaar, E., Parren, P., Weigel, D., and Nusse, R. 1987. The Drosophila homolog of the mouse mammary oncogene int -1 is identical to the segment polarity gene wingless. Cell 50: 649-657.

Robbins, D., Nybakken, K., Kobayashi, R., Sisson, J., Bishop, J., and Thérond, P. 1997. Hedgehog elicits signal transduction by means of a large complex containing the kinesin-related protein Costal2. Cell 90: 225-234.

Roberts, D.J., Johnson, R.L., Burke, A.C., Nelson, C.E., Morgan, B.A., and Tabin, C. 1995. Sonic hedgehog is an endodermal signal inducing Bmp-4 and Hox genes during induction and regionalization of the chick hindgut. Development 121: 3163-3174.

Roelink, H., Augsburger, A., Heemskerk, J., Korzh, V., Norlin, S., Ruiz i Altaba, A., Tanabe, Y., Placzek, M., Edlund, T., Jessell, T., et al. 1994. Floor plate and motor neuron induction by vhh-1, a vertebrate homolog of hedgehog expressed by the notochord. Cell 76: 761-775.

Roelink, H., Porter, J., Chiang, C., Tanabe, Y., Chang, D., Beachy, P., and Jessell, T. 1995. Floor plate and motor neuron induction by different concentrations of the amino terminal cleavage product of Sonic hedgehog autoproteolysis. Cell 81: 445-455.

Roessler, E., Belloni, E., Gaudenz, K., Jay, P., Berta, P., Scherer, S., Tsui, L., and Muenke, M. 1996. Mutations in the human Sonic hedgehog gene cause holoprosencephaly. Nat. Genet.
14: 357-360.

Rowitch, D., St-Jacques, B., Lee, S., Flax, J., Snyder, E., and McMahon, A. 1999. Sonic hedgehog regulates proliferation and inhibits differentiation of CNS precursor cells. J. Neurosci. 19: 8954-8965.

Roy, S., Qiao, T., Wolff, C., and Ingham, P. 2001. Hedgehog signalling pathway is essential for pancreas specification in the zebrafish embryo. Curr. Biol. 11: 1358-1363.

Ruiz i Altaba, A. 1998. Combinatorial Gli gene function in floor plate and neuronal inductions by Sonic hedgehog. Development 125: 2203-2212.

-1999. Gli proteins encode context-dependent positive and negative functions: Implications for development and disease. Development 126: 3205-3216.

Sampedro, J., Johnston, P., and Lawrence, P.A. 1993. A role for wingless in the segmental gradient of Drosophila? Development 117: 677-687.

Sanz-Ezquerro, J. and Tickle, C. 2000. Autoregulation of Shh expression and Shh induction of cell death suggest a mechanism for modulating polarising activity during chick limb development. Development 127: 4811-4823.

Sasaki, H., Hui, C., Nakafuku, M., and Kondoh, H. 1997. A binding-site for Gli proteins is essential for Hnf3b floor plate enhancer activity in transgenics and can respond to Shh in vitro. Development 124: 1313-1322.

Sasaki, H., Nishizaki, Y., Hui, C., Nakafuku, M., and Kondoh, H. 1999. Regulation of Gli2 and Gli3 activities by an aminoterminal repression domain: Implication of Gli2 and Gli3 as primary mediators of Shh signaling. Development 126: 3915-3924.

Sato, N., Leopold, P., and Crystal, R. 1999. Induction of the hair growth phase in postnatal mice by localized transient expression of Sonic hedgehog. J. Clin. Invest. 104: 855-864.

Schilling, T.F., Concordet, J.-P., and Ingham, P.W. 1999. Regulation of left-right asymmetries in the zebrafish by Shh and BMP4. Dev. Biol. 210: 277-287.

Schnepp, B., Grumbling, G., Donaldson, T., and Simcox, A. 1996. Vein is a novel component in the Drosophila epidermal growth factor receptor pathway with similarity to the neuregulins. Genes \& Dev. 10: 2302-2313.

Shimeld, S. 1999. The evolution of the hedgehog gene family in chordates: Insights from amphioxus hedgehog. Dev. Genes Evol. 209: 40-47.

Soula, C., Danesin, C., Kan, P., Grob, M., Poncet, C., and Cochard, P. 2001. Distinct sites of origin of oligodendrocytes and somatic motoneurons in the chick spinal cord: Oligodendrocytes arise from $\mathrm{Nkx} 2.2$-expressing progenitors by a Shh-dependent mechanism. Development 128: 1369-1379.

St-Jacques, B., Dassule, H., Karavanova, I., Botchkarev, V., Li, J., Danielian, P., McMahon, J., Lewis, P., Paus, R., and McMahon, A. 1998. Sonic hedgehog signaling is essential for hair development. Curr. Biol. 8: 1058-1068.

St-Jacques, B., Hammerschmidt, M., and McMahon, A. 1999. Indian hedgehog signaling regulates proliferation and differentiation of chondrocytes and is essential for bone formation. Genes \& Dev. 13: 2072-2086.

Stegman, M., Vallance, J., Elangovan, G., Sosinski, J., Cheng, Y., and Robbins, D. 2000. Identification of a tetrameric hedgehog signaling complex. J. Biol. Chem. 275: 21809-21812.

Stenkamp, D.L., Frey, R.A., Prabhudesai, S.N., and Raymond, P.A. 2000. Function for Hedgehog genes in zebrafish retinal development. Dev. Biol. 220: 238-252.

Stickens, D., Clines, G., Burbee, D., Ramos, P., Thomas, S. Hogue, D., Hecht, J.T., Lovett, M., and Evans, G.A. 1996. The EXT2 multiple exostoses gene defines a family of putative tumor suppressor genes. Nat. Genet. 14: 25-32. 
Stone, D., Hynes, M., Armanini, M., Swanson, T., Gu, Q., Johnson, R., Scott, M., Pennica, D., Goddard, A., Phillips, H., et al. 1996. The tumor-suppressor gene patched encodes a candidate receptor for Sonic hedgehog. Nature 384: 129-134.

Strigini, M. and Cohen, S.M. 1997. A hedgehog activity gradient contributes to AP axial patterning of the Drosophila wing. Development 124: 4697-4705.

Struhl, G., Barbash, D., and Lawrence, P. 1997. Hedgehog organizes the pattern and polarity of epidermal cells in the Drosophila abdomen. Development 124: 2143-2154.

Strutt, H., Thomas, C., Nakano, Y., Stark, D., Neave, B., Taylor, A.M., and Ingham, P.W. 2001. Mutations in the sterol sensing domain of Patched suggest a role for vesicular trafficking in Smoothened regulation. Curr. Biol 11: 608-613.

Sukegawa, A., Narita, T., Kameda, T., Saitoh, K., Nohno, T., Iba, H., Yasugi, S., and Fukuda, K. 2000. The concentric structure of the developing gut is regulated by Sonic hedgehog derived from endodermal epithelium. Development 127: 1971-1980.

Szebenyi, G. and Fallon, J. 1999. Fibroblast growth factors as multifunctional signaling factors. Int. Rev. Cytol. 185: 45106.

Tabata, T. and Kornberg, T. 1994. Hedgehog is a signalling protein with a key role in patterning Drosophila imaginal discs. Cell 76: 89-102.

Tabata, T., Eaton, S., and Kornberg, T.B. 1992. The Drosophila hedgehog gene is expressed specifically in posterior compartment cells and is a target of engrailed regulation. Genes \& Dev. 6: 2635-2645.

Tabin, C. 1991. Retinoids, homeoboxes, and growth factors: Toward molecular models for limb development. Cell 66: 199217.

Taipale, J. and Beachy, P. 2001. The Hedgehog and Wnt signalling pathways in cancer. Nature 411: 349-354.

Taipale, J., Chen, J., Cooper, M., Wang, B., Mann, R., Milenkovic, L., Scott, M., and Beachy, P. 2000. Effects of oncogenic mutations in Smoothened and Patched can be reversed by cyclopamine. Nature 406: 1005-1009.

Tanimoto, H., Itoh, S., ten Dijke, P., and Tabata, T. 2000. Hedgehog creates a gradient of DPP activity in Drosophila wing imaginal discs. Mol. Cell 5: 59-71.

Tashiro, S., Michiue, T., Higashijima, S., Zenno, S., Ishimaru, S., Takahashi, F., Orihara, M., Kojima, T., and Saigo, K. 1993. Structure and expression of hedgehog, a Drosophila segment-polarity gene required for cell-cell communication. Gene 124: 183-189.

Taylor, A.M., Nakano, Y., Mohler, J., and Ingham, P.W. 1993. Contrasting distributions of patched and hedgehog proteins in the Drosophila embryo. Mech. Dev. 43: 89-96.

Taylor, F.R., Wen, D., Garber, E.A., Carmillo, A.N., Baker, D.P., Arduini, R.M., Williams, K.P., Weinreb, P.H., Rayhorn, P., Hronowski, X., et al. 2001. Enhanced potency of human Sonic hedgehog by hydrophobic modification. Biochemistry 40: 4359-4371.

Teillet, M., Watanabe, Y., Jeffs, P., Duprez, D., Lapointe, F., and Le Douarin, N. 1998. Sonic hedgehog is required for survival of both myogenic and chondrogenic somitic lineages. Development 125: 2019-2030.

Teleman, A. and Cohen, S. 2000. Dpp gradient formation in the Drosophila wing imaginal disc. Cell 103: 971-980.

Thé, I., Bellaiche, Y., and Perrimon, N. 1999. Hedgehog movement is regulated through tout velu-dependent synthesis of a heparan sulfate proteoglycan. Mol. Cell 4: 633-639.

Therond, P., Limbourg Bouchon, B., Gallet, A., Dussilol, F., Pietri, T., van den Heuvel, M., and Tricoire, H. 1999. Differential requirements of the Fused kinase for Hedgehog signalling in the Drosophila embryo. Development 126: 4039-
4051.

Thomas, M., Lee, J., Rastalsky, N., and Habener, J. 2001. Hedgehog signaling regulation of homeodomain protein islet duodenum homeobox-1 expression in pancreatic $\beta$-cells. Endocrinology 142: 1033-1040.

Ting-Berreth, S.A. and Chuong, C.M. 1996. Sonic hedgehog in feather morphogenesis: Induction of mesenchymal condensation and association with cell death. Dev. Dyn. 207: 157170 .

Tole, S. and Ragsdale, C. 2000. Dorsoventral patterning of the telencephalon is disrupted in the mouse mutant extratoes(J). Dev. Biol. 217: 254-265.

Treier, M., O'Connell, S., Gleiberman, A., Price, J., Szeto, D. Burgess, R., Chuang, P., McMahon, A., and Rosenfeld, M. 2001. Hedgehog signaling is required for pituitary gland development. Development 128: 377-386.

Tsukui, T., Capdevila, J., Tamura, K., Ruiz-Lozano, P., Rodriguez-Esteban, C., Yonei-Tamura, S., Magallon, J., Chandraratna, R.A., Chien, K., Blumberg, B., et al. 1999. Multiple left-right asymmetry defects in $S h h^{-1-}$ mutant mice unveil a convergence of the Shh and retinoic acid pathways in the control of Lefty-1. Proc. Natl. Acad. Sci. 96: 11376-11381.

Umehara, F., Tate, G., Itoh, K., Yamaguchi, N., Douchi, T., Mitsuya, T., and Osame, M. 2000. A novel mutation of desert hedgehog in a patient with 46,XY partial gonadal dysgenesis accompanied by minifascicular neuropathy. Am. I. Hum. Genet. 67: 1302-1305.

van den Heuvel, M. and Ingham, P.W. 1996. smoothened encodes a serpentine protein required for hedgehog signaling. Nature 382: 547-551.

van Eeden, F., Granato, M., Schach, U., Brand, M., Furutaniseiki, M., Haffter, P., Hammerschmidt, M., Heisenberg, C., Jiang, Y., Kane, D., et al. 1996. Mutations affecting somite formation and patterning in the zebrafish, Danio rerio. Development 123: 153-164.

Veitch, E. and Begbie, J. 1999. Pharyngeal arch patterning in the absence of neural crest. Curr. Biol 9: 1481-1484.

Vervoort, M., Crozatier, M., Valle, D., and Vincent, A. 1999. The COE transcription factor Collier is a mediator of shortrange Hedgehog-induced patterning of the Drosophila wing. Curr. Biol. 9: 632-639.

Villavicencio, E., Walterhouse, D., and Iannaccone, P. 2000. The sonic hedgehog-patched-gli pathway in human development and disease. Am. J. Hum. Genet. 67: 1047-1054.

von Mering, C. and Basler, K. 1999. Distinct and regulated activities of human Gli proteins in Drosophila. Curr. Biol. 9: $1319-1322$

Vortkamp, A., Lee, K., Lanske, B., Segre, G.V., Kronenberg, H.M., and Tabin, C. 1996. Indian hedgehog and parathyroid hormone-related protein regulate the rate of cartilage differentiation. Science 273: 613-622.

Wallace, V. 1999. Purkinje-cell-derived Sonic hedgehog regulates granule neuron precursor cell proliferation in the developing mouse cerebellum. Curr. Biol. 9: 445-448.

Wallace, V. and Raff, M. 1999. A role for Sonic hedgehog in axon-to-astrocyte signalling in the rodent optic nerve. Development 126: 2901-2909.

Wang, B., Fallon, J., and Beachy, P. 2000. Hedgehog-regulated processing of Gli3 produces an anterior/posterior repressor gradient in the developing vertebrate limb. Cell 100: 423434.

Wang, G., Amanai, K., Wang, B., and Jiang, J. 2000. Interactions with Costal2 and suppressor of fused regulate nuclear translocation and activity of cubitus interruptus. Genes \& Dev. 14: 2893-2905.

Wang, M. and Jin, P. 1995. Induction of dopaminergic neuron 
phenotype in the midbrain by Sonic hedgehog protein. Nat. Med. 1: 1184-1188.

Wang, Q. and Holmgren, R. 1999. The subcellular localization and activity of Drosophila cubitus interruptus are regulated at multiple levels. Development 126: 5097-5106.

. 2000. Nuclear import of cubitus interruptus is regulated by hedgehog via a mechanism distinct from Ci stabilization and Ci activation. Development 127: 3131-3139.

Watanabe, Y. and H, N. 2000. Control of chick tectum territory along dorsoventral axis by Sonic hedgehog. Development 127: $1131-1140$

Wechsler-Reya, R. and Scott, M. 1999. Control of neuronal precursor proliferation in the cerebellum by Sonic Hedgehog. Neuron 22: 103-114.

Wiellette, E. and McGinnis, W. 1999. Hox genes differentially regulate Serrate to generate segment-specific structures. Development 126: 1985-1995.

Williams, Z., Tse, V., Hou, L., Xu, L., and Silverberg, G. 2000. Sonic hedgehog promotes proliferation and tyrosine hydroxylase induction of postnatal sympathetic cells in vitro. Neuroreport 11: 3315-3319.

Wodarz, A. and Nusse, R. 1998. Mechanisms of Wnt signaling in development. Annu. Rev. Cell Dev. Biol. 14: 59-88.

Wolfgang, W.J., Hoskote, A., Roberts, I.J., Jackson, S., and Forte, M. 2001. Genetic analysis of the Drosophila Gs $\alpha$ gene. Genetics 158: 1189-1201.

Xie, J. Murone, M., Luoh, S., Ryan, A., Gu, Q., Zhang, C., Bonifas, J., Lam, C., Hynes, M., Goddard, A., et al. 1998. Activating smoothened mutations in sporadic basal-cell carcinoma. Nature 391: 90-92.

Yang, Y., Drossopoulou, G., Chuang, P., Duprez, D., Marti, E., Bumcrot, D., Vargesson, N., Clarke, J., Niswander, L., McMahon, A., et al. 1997. Relationship between dose, distance and time in Sonic Hedgehog-mediated regulation of anteroposterior polarity in the chick limb. Development 124: 4393-4404

Ye, W., Shimamura, K., Rubenstein, J., Hynes, M., and Rosenthal, A. 1998. FGF and Shh signals control dopaminergic and serotonergic cell fate in the anterior neural plate. Cell 93: 755-766.

Yoshida, E., Noshiro, M., Kawamoto, T., Tsutsumi, S., Kuruta, Y., and Kato, Y. 2001. Direct inhibition of Indian hedgehog expression by parathyroid hormone (PTH)/PTH-related peptide and up-regulation by retinoic acid in growth plate chondrocyte cultures. Exp. Cell. Res. 265: 64-72.

Zecca, M., Basler, K., and Struhl, G. 1995. Sequential organizing activities of engrailed, hedgehog and decapentaplegic in the Drosophila wing. Development 121: 2265-2278.

Zeng, X., Goetz, J., Suber, L., Scott, W.J., Schreiner, C., and Robbins, D. 2001. A freely diffusible form of Sonic hedgehog mediates long-range signalling. Nature 411: 716-720.

Zhang, X. and Yang, X. 2001a. Regulation of retinal ganglion cell production by Sonic hedgehog. Development 128: 943 957.

- 2001b. Temporal and spatial effects of Sonic hedgehog signaling in chick eye morphogenesis. Dev. Biol. 233: 271290.

Zhang, X.M., Ramalho-Santos, M., and McMahon, A.P. 2001. Smoothened mutants reveal redundant roles for Shh and Ihh signaling including regulation of $\mathrm{L} / \mathrm{R}$ asymmetry by the mouse node. Cell 105: 781-792.

Zhang, Y. and Kalderon, D. 2000. Regulation of cell proliferation and patterning in Drosophila oogenesis by Hedgehog signaling. Development 127: 2165-2176.

Zhang, Y., Zhang, Z., Zhao, X., Yu, X., Hu, Y., Geronimo, B., Fromm, S., and Chen, Y. 2000. A new function of BMP4:
Dual role for BMP4 in regulation of Sonic hedgehog expression in the mouse tooth germ. Development 127: 1431-143. 


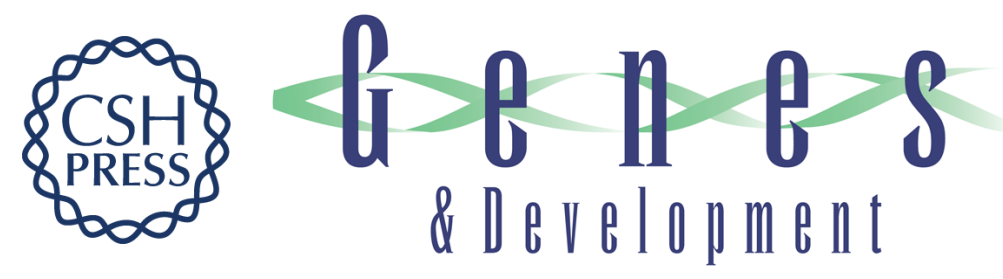

\section{Hedgehog signaling in animal development: paradigms and principles}

Philip W. Ingham and Andrew P. McMahon

Genes Dev. 2001, 15:

Access the most recent version at doi:10.1101/gad.938601

\section{License}

Email Alerting Receive free email alerts when new articles cite this article - sign up in the box at the top Service right corner of the article or click here.

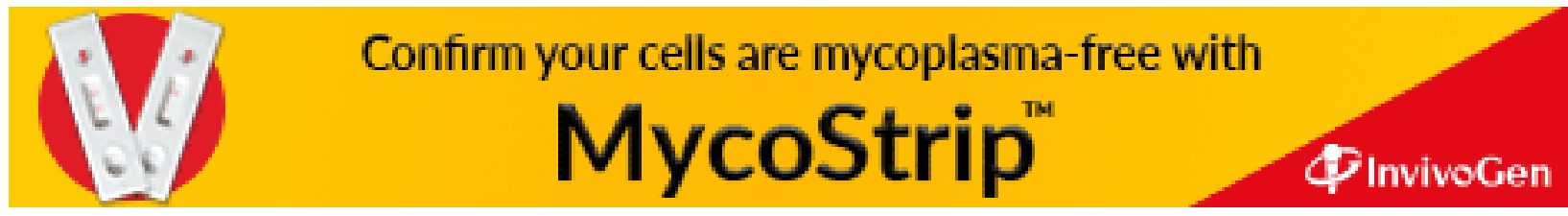

